\title{
The Cumulus And Stratocumulus CloudSat-CALIPSO Dataset (CASCCAD)
}

\author{
Grégory Cesana $^{1,2}$, Anthony D. Del Genio ${ }^{2}$, and Hélène Chepfer ${ }^{3,4}$ \\ ${ }^{1}$ Columbia University, Center for Climate Systems Research, Earth Institute, New York, NY, USA \\ ${ }^{2}$ NASA Goddard Institute for Space Studies, New York, NY, USA \\ ${ }^{3}$ LMD/IPSL, Sorbonne Université, Paris, France \\ ${ }^{4}$ LMD/IPSL, CNRS, École Polytechnique, Palaiseau, France \\ Correspondence: Gregory V. Cesana (gregory.cesana@columbia.edu) \\ Received: 7 May 2019 - Discussion started: 22 May 2019 \\ Revised: 6 September 2019 - Accepted: 23 September 2019 - Published: 25 November 2019
}

\begin{abstract}
Low clouds continue to contribute greatly to the uncertainty in cloud feedback estimates. Depending on whether a region is dominated by cumulus $(\mathrm{Cu})$ or stratocumulus $(\mathrm{Sc})$ clouds, the interannual low-cloud feedback is somewhat different in both spaceborne and large-eddy simulation studies. Therefore, simulating the correct amount and variation of the $\mathrm{Cu}$ and $\mathrm{Sc}$ cloud distributions could be crucial to predict future cloud feedbacks. Here we document spatial distributions and profiles of $\mathrm{Sc}$ and $\mathrm{Cu}$ clouds derived from Cloud-Aerosol Lidar and Infrared Pathfinder Satellite Observations (CALIPSO) and CloudSat measurements. For this purpose, we create a new dataset called the Cumulus And Stratocumulus CloudSat-CALIPSO Dataset (CASCCAD), which identifies $\mathrm{Sc}$, broken $\mathrm{Sc}, \mathrm{Cu}$ under $\mathrm{Sc}, \mathrm{Cu}$ with stratiform outflow and $\mathrm{Cu}$. To separate the $\mathrm{Cu}$ from $\mathrm{Sc}$, we design an original method based on the cloud height, horizontal extent, vertical variability and horizontal continuity, which is separately applied to both CALIPSO and combined CloudSat-CALIPSO observations. First, the choice of parameters used in the discrimination algorithm is investigated and validated in selected $\mathrm{Cu}, \mathrm{Sc}$ and $\mathrm{Sc}-\mathrm{Cu}$ transition case studies. Then, the global statistics are compared against those from existing passive- and active-sensor satellite observations. Our results indicate that the cloud optical thickness - as used in passive-sensor observations - is not a sufficient parameter to discriminate $\mathrm{Cu}$ from Sc clouds, in agreement with previous literature. Using clustering-derived datasets shows better results although one cannot completely separate cloud types with such an approach. On the contrary, classifying $\mathrm{Cu}$ and $\mathrm{Sc}$ clouds and the transition between them based on their geometrical shape and spatial heterogeneity leads to spatial distributions consistent with prior knowledge of these clouds, from ground-based, ship-based and field campaigns. Furthermore, we show that our method improves existing $\mathrm{Sc}-\mathrm{Cu}$ classifications by using additional information on cloud height and vertical cloud fraction variation. Finally, the CASCCAD datasets provide a basis to evaluate shallow convection and stratocumulus clouds on a global scale in climate models and potentially improve our understanding of low-level cloud feedbacks. The CASCCAD dataset (Cesana, 2019, https://doi.org/10.5281/zenodo.2667637) is available on the Goddard Institute for Space Studies (GISS) website at https://data.giss.nasa.gov/clouds/casccad/ (last access: 5 November 2019) and on the zenodo website at https://zenodo.org/record/2667637 (last access: 5 November 2019).
\end{abstract}




\section{Introduction}

Whether clouds will amplify or dampen global warming, referred to as cloud feedbacks, continues to be a dominant source of uncertainty in future climate projections, for which low clouds over the tropics and at midlatitudes contribute up to $50 \%$ in recent generations of the Coupled Model Intercomparison Project (CMIP) models (Zelinka et al., 2016). Low clouds (i.e., cloud top height lower than $\sim 3 \mathrm{~km}$ ) may be separated into two main categories: stratocumulus (Sc, including stratus clouds) and cumulus $(\mathrm{Cu})$. Driven by radiative cooling, Sc clouds cap the planetary boundary layer (PBL) over cool oceans in conditions with a strong cloud top inversion, mostly off the western coasts of continents (e.g., Klein and Hartmann, 1993). They are typically hundreds of meters thick with a large horizontal extent, which can be either homogeneous (in decks) or heterogenous (open and closed cells), and a stable cloud top height. Due to their large cloud cover, these clouds strongly reflect shortwave (SW) radiation and contribute to surface cooling. As the ocean warms up further west in the trade-wind regions, the latent heat flux increases and the convection becomes surface driven, therefore favoring breaking up of Sc and the subsequent formation of $\mathrm{Cu}$ clouds (Albrecht et al., 2019; Wyant et al., 1997). These clouds are horizontally limited and scattered - i.e., with a modest cloud cover - and their tops can rise above the PBL. Since these low clouds are governed by distinct processes, they may respond differently to climate warming (e.g., Bretherton, 2015), and there is no fundamental reason to expect the two cloud types to exhibit the same feedback.

Idealized large-eddy simulation (LES) studies have partly supported the hypothesis of different cloud-type responses to climate warming, i.e., a substantial decrease of Sc as opposed to a moderate decrease to no change for $\mathrm{Cu}$, yet the underlying processes remain poorly understood, particularly for trade-wind $\mathrm{Cu}$ (Bretherton, 2015). Furthermore, recent satellite-based studies have shown that the interannual lowcloud feedback in response to sea surface temperature (SST) forcings is somewhat different depending on whether a region is dominated by $\mathrm{Cu}$ or Sc clouds (Cesana et al., 2019a; McCoy et al., 2017). Therefore, simulating the right amount of $\mathrm{Cu}$ and $\mathrm{Sc}$ clouds could be crucial for models to reproduce the overall interannual low-cloud feedback as observed from space (Cesana et al., 2019a) and to predict future cloud feedbacks (Klein and Hall, 2015). Yet the relatively scarce amount of observations that fundamentally distinguish Sc and $\mathrm{Cu}$ clouds (mostly field campaigns and ground-based sites, i.e., Zhou et al., 2015; Rémillard et al., 2012) limits our ability to study the present-day global distribution of these clouds and their response to surface warming, and hence to better constrain the climate models.

Estimating the global radiative impact of clouds on past, present and future climate continues to be a challenging question that requires observations of cloud macrophysical (e.g., height, spatial extent) and microphysical (e.g., phase, effective radius) properties on a global scale. Knowledge of the cloud type provides only a little leverage on determining their radiative properties, which may explain why cloud-type classification has received far less attention in the past. The first global-scale cloud-type observations were collected visually from land stations and ships in the 1950s, and were subsequently compiled to make a coarse digital database in the late 1980s (Warren et al., 1988) and were updated a couple of decades after (Warren et al., 2007). A few years later, the first global-scale cloud-type climatology derived from passive-sensor satellites emerged, based on cloud top pressure (CTP) and cloud optical thickness (COT) (Rossow and Schiffer, 1991, 1999). While very useful because of its longterm record, large spatial cover and finer resolution than Warren et al. (1988), such datasets suffer from both methodology and instrumental limitations that make it difficult to fully discriminate $\mathrm{Sc}$ from $\mathrm{Cu}$ clouds. The CTP-COT method does not exploit information on the spatial shape of an individual cloud, that is to say its horizontal and vertical extent, and thus is not always accurate (Hahn et al., 2001; Pincus et al., 1999). Additionally, passive-sensor satellites do not describe the entire profile but only the uppermost layers, integrated over a height that is moreover hard to quantify with less confidence over land and in regions of strong inversions (Garay et al., 2008; Marchand et al., 2010). Thus, low cloud cover in regions of extensive higher clouds is underestimated. Finally, some instruments may not be well suited for $\mathrm{Cu}$ cloud detection (Marchand et al., 2010).

By combining collocated observations from the active CloudSat Cloud Profiling Radar (CPR, Stephens et al., 2002) and Cloud-Aerosol Lidar and Infrared Pathfinder Satellite Observations (CALIPSO; Winker et al., 2010) lidar and passive Moderate Resolution Imaging Spectroradiometer (MODIS; King et al., 2013) spectrometer, the 2B-CLDCLASS-LIDAR product (Sassen and Wang, 2008; Wang et al., 2013) addresses most of the above caveats. It classifies clouds into eight types based on cloud vertical and horizontal extent, reflectivity, precipitating state, temperature, height and brightness (Huang et al., 2015). However, this combined dataset is only available for a relatively short period of time (about 4.5 years), which influences statistical correlations between environment variables and cloud fraction (e.g., Cesana et al., 2019a; Klein et al., 2017). Although the radar-only product extends over a longer time period (for daytime only; see Sect. 2.2), the CPR is less sensitive to fractionated and thin shallow cumulus clouds than the CALIPSO lidar, and its ground clutter prevents cloud detection below $1 \mathrm{~km}$, which precludes the detection of a large amount of marine low-level clouds (mostly $\mathrm{Sc}$ and $\mathrm{Cu}$ clouds, Liu et al., 2016). Furthermore, the CPR horizontal resolution $(\sim 1.4 \mathrm{~km} \times 1.7 \mathrm{~km})$ is not ideal for shallow cumulus detection, which are typically smaller than $1 \mathrm{~km}$ (Rodts et al., 2003; Zhang and Klein, 2013). Therefore, creating a specific $\mathrm{Sc}-\mathrm{Cu}$ cloud classification product based on CALIPSO 
observations only would allow one to overcome these issues although confining the analysis to regions with optically thin or no overlying high clouds.

Here we propose documenting spatial distributions and profiles of $\mathrm{Sc}, \mathrm{Cu}$ and transitioning (i.e., broken Sc, $\mathrm{Cu}$ under $\mathrm{Sc}$ and $\mathrm{Cu}$ with stratiform outflow) clouds derived from CALIPSO measurements. To achieve this goal, we create an original method based on the cloud height, horizontal extent, vertical variability and horizontal continuity, which can be applied separately to both CALIPSO and combined CloudSat-CALIPSO observations, referred to as the Cumulus And Stratocumulus CloudSat-CALIPSO Dataset (CASCCAD, Cesana, 2019; https://doi.org/10.5281/zenodo.2667637). The datasets are presented in Sect. 2. The sensitivity of the CASCCAD algorithm is assessed in Sect. 3, and the global-scale results are then discussed and compared to a subset of existing cloudtype datasets in Sect. 4. Finally, Sect. 5 summarizes the results.

\section{Datasets}

In this section, we describe the CALIPSO (GOCCP, Sect. 2.1) and the combined CloudSat-CALIPSO (RLGeoProf, Sect. 2.2) observations that we use with the CASCCAD algorithm and the only other active-sensor cloud-type product available (2B-CLDCLASS-LIDAR, Sect. 2.3). The CASCCAD algorithm (see full description in Sect. 3) is designed so that it can be applied to active-sensor level 2 observations (i.e., cloud mask at the orbital level) at their native resolution to generate level $2 \mathrm{Sc}-\mathrm{Cu}$ cloud mask profiles, which consist of along-track profiles of $\mathrm{Sc}, \mathrm{Cu}$ and transitioning (i.e., broken $\mathrm{Sc}, \mathrm{Cu}$ under $\mathrm{Sc}$ and $\mathrm{Cu}$ with stratiform outflow) cloud types. Here we separately apply CASCCAD to GOCCP and CloudSat-CALIPSO RL-GeoProf. The resulting GOCCP- or CloudSat-CALIPSO-CASCCAD Cu-Sc profiles are then accumulated onto a $2.5^{\circ} \times 2.5^{\circ}$ grid $(2-\mathrm{D}$ cloud fraction) and over $40480 \mathrm{~m}$ levels (3-D cloud fraction) for each month to create level 3 files (i.e., cloud fraction on the global scale). A detailed description of the content of both the GOCCP and RL-GeoProf CASCCAD level 3 files - averaged over the whole period of time, 2007 to 2016 for GOCCP and 2007 to 2010 for RL-GeoProf - is available on the CASCCAD website: https://data.giss.nasa.gov/ clouds/casccad/ (last access: 5 November 2019). To summarize, the distinct GOCCP and RL-GeoProf CASCCAD datasets contain 2-D and 3-D cloud fraction of all-low, $\mathrm{Cu}, \mathrm{Sc}$ and transitioning (i.e., broken $\mathrm{Sc}, \mathrm{Cu}$ under $\mathrm{Sc}$ and $\mathrm{Cu}$ with stratiform outflow) cloud type. Finally, the GOCCP and RLGeoProf level 2 files (i.e., along-track $\mathrm{Cu}-\mathrm{Sc}$ mask at native resolution for each granule/orbit) are not yet available on the website (as of August 2019) but can be made available upon request.

\subsection{GOCCP}

The instantaneous cloud mask of the global circulation model (GCM)-oriented CALIPSO Cloud Product (GOCCP) version 3.1.2 (Guzman et al., 2017) is used by our discrimination algorithm (referred to as DA, described in Sect. 3.2) to derive $\mathrm{Sc}-\mathrm{Cu}$ cloud fraction statistics from 2007 to 2016 over a $2.5^{\circ}$ grid and for 40 levels with $480 \mathrm{~m}$ spacing from 0 to $19.2 \mathrm{~km}$. GOCCP (Chepfer et al., 2010) was developed to facilitate the evaluation of cloud properties in GCMs when combined with a lidar simulator (Chepfer et al., 2008) that uses the same cloud definitions, and it ensures a consistent comparison between observations and simulations (Cesana and Waliser, 2016). The ratio of the attenuated total backscatter signal (ATB) to the molecular ATB - so-called scattering ratio (SR) - is computed from the level 1B CALIPSO files for every $333 \mathrm{~m}$ along-track-resolution near-nadir lidar profile for $480 \mathrm{~m}$ height intervals. This lidar-based quantity is a proxy of the presence of particulate matter in a layer. GOCCP uses a fixed SR threshold to detect clouds ( SR > 5), for either daytime or nighttime data, regardless of the vertical level. This threshold allows the detection of thin cirrus cloud in the high troposphere (McGill et al., 2007), hence the majority - if not all - of optically thicker PBL clouds except when masked by overlying high clouds (e.g., the trade-wind regions). It also prevents most false detections of aerosol layers as being cloudy in the PBL (Chepfer et al., 2013). GOCCP has been validated against in situ (Cesana et al., 2016) and ground-based observations (Lacour et al., 2017). Caveats for this dataset are discussed in Cesana et al. (2016) and in Cesana and Waliser (2016). Compared to GOCCP version 2.9 (Cesana et al., 2016), version 3.1.2 improves the detection of fully attenuated pixels by introducing a surface echo detection. When no lidar echo is detected, pixels below the lowest cloudy pixel are diagnosed as being fully attenuated and therefore not accounted for in the cloud fraction computation. This new feature reduces the underestimation of the cloud fraction underneath optically thick liquid-topped clouds in the lower troposphere (Cesana et al., 2016).

\subsection{CloudSat-CALIPSO RL-GeoProf}

Additionally, the $\mathrm{Sc}-\mathrm{Cu} \mathrm{DA}$ is applied to combined CloudSat-CALIPSO profiles (using the radar-lidar geometrical profile product (RL-GeoProf), Mace and Zhang, 2014; version R04) from 2007 to 2010 over a $2.5^{\circ}$ grid and for 80 levels with $240 \mathrm{~m}$ spacing from 0 to $19.2 \mathrm{~km}$. From its launch to early April 2011, CloudSat flew approximately $15 \mathrm{~s}$ ahead of CALIPSO, making it possible to observe the same scene from a lidar-radar perspective when using both the 2B-GEOPROF and 2B-GEOPROF-LIDAR products (Mace and Zhang, 2014). CloudSat experienced a severe anomaly in April 2011, which forced the satellite to leave the A-Train constellation before coming back in June 2012 in "Daylight Only Operation mode" (DO-Op). As a result, 
CloudSat-CALIPSO combined observations are only available for 4.5 years. The CPR cloud mask provides confidence levels for the cloud detection (Marchand et al., 2009). Following Mace and Zhang (2014), we chose the confidence level of 20 and higher to characterize the presence of a cloud from the radar cloud mask. The CPR has a coarser horizontal $(\sim 1.4 \mathrm{~km} \times 1.7 \mathrm{~km})$ and vertical resolution $(240 \mathrm{~m})$ than the CALIPSO lidar $(\Delta z=30 \mathrm{~m}$ below $8 \mathrm{~km}$ and $60 \mathrm{~m}$ above $8 \mathrm{~km}$ for $\sim 70 \mathrm{~m}$ footprint every $333 \mathrm{~m}$ ). As a result, several lidar profiles fall within the CloudSat radar footprint most of the time. These are used to compute the lidar cloud fraction $\left(\mathrm{CF}_{\text {lidar }}\right.$, from 0 to 1$)$ based on the CALIPSO Vertical Feature Mask (VFM) of the level $25 \mathrm{~km}$ CALIPSO files (Vaughan et al., 2009), at the CPR resolution in the 2BGEOPROF-LIDAR files. While the $\mathrm{CF}_{\text {lidar }}$ can sometimes be lower than 0.5 , we kept the 0.5 threshold to diagnose the presence of a cloud as in Mace and Zhang (2014) and Cesana et al. (2019b). Diagnosing a pixel as cloudy from values below 0.5 may result in an overestimate of the averaged cloud fraction when compared to ground-based measurements (Fig. S1 in the Supplement and Marchand et al., 2010).

\subsection{B-CLDCLASS-LIDAR}

The 2B-CLDCLASS-LIDAR product R05 (Sassen and Wang, 2008; Wang et al., 2013; referred to as 2BCCL in the remainder of the paper) merges collocated observations from the CloudSat CPR, CALIPSO lidar and MODIS spectrometer to classify clouds into eight types based on several criteria: their vertical and horizontal extent, their precipitating state, their temperature and their radiance. Although eight cloud types are available in this dataset (deep convective, cirrus, nimbostratus, altostratus, altocumulus, cumulus including fair-weather and congestus, stratus and stratocumulus), we only focus on the $\mathrm{Cu}$, stratus ( $\mathrm{St}$ ) and $\mathrm{Sc}$ cloud types. The $\mathrm{St}$ and Sc cloud types are combined into a single category referred to as Sc for consistency with the Sc-Cu discrimination algorithm, which does not differentiate between these two categories. In addition, the Sc and St clouds are particularly difficult to distinguish in the $2 \mathrm{BCCL}$ product because of the ground clutter contamination in the radar signal (Sassen and Wang, 2008) as shown by Huang et al. (2015). In 2BCCL, the cloud base and top are given for up to 10 cloudy layers, which is why we reproject these cloudy layers onto a $480 \mathrm{~m}$ vertical grid from 0 to $19.2 \mathrm{~km}$ to be consistent with the GOCCP and RL-GeoProf datasets described in Sect. 2.1 and 2.2. Those are then accumulated into a $2.5^{\circ} \times 2.5^{\circ}$ grid as for the two other products. Note that there are substantial differences between results using the R04 and R05 versions, which is why the reader should refer to the original manuscript published in 22 May 2019 on the ESSD discussion website for results using the older R04 version.

\section{Description of the Cumulus And Stratocumulus CloudSat-CALIPSO Dataset (CASCCAD) discrimination algorithm}

\subsection{Why choose GOCCP and CloudSat-CALIPSO RL-GeoProf?}

The main goal of this study is to document spatial distributions and profiles of $\mathrm{Sc}$ and $\mathrm{Cu}$ clouds on a global scale, with the desire to further analyze long-term relationships between $\mathrm{Sc}-\mathrm{Cu}$ clouds and environmental parameters in future studies. For this purpose, we need to (i) distinguish the two cloud types based on observable cloud properties and (ii) use datasets that are available for a time period sufficiently long ( $\sim 10$ years) to compute statistically significant relationships (e.g., using 4 years of GOCCP rather than 10 may decrease the amplitude of the relationship between low clouds and SST anomalies by more than $15 \%$, Cesana et al., 2019a). Although both $\mathrm{Sc}$ and $\mathrm{Cu}$ clouds form within the planetary boundary layer (PBL), they have relatively different shapes as they are controlled by different physical mechanisms. However, one cannot separate clouds according to the mechanisms that form them as GCMs do using different PBL and convective parameterizations, which is why we choose to use the morphology to discriminate cloud types in this study. The $\mathrm{Cu}$ (Fig. 1, second to last column) can stretch up past the PBL into the lower free troposphere $(z \sim 3 \mathrm{~km})$ while they have typically a small horizontal extent (no more than a few kilometers, e.g, Lamer et al., 2015; Nuijens et al., 2015b). On the contrary, the Sc (Fig. 1, first column) have a relatively small vertical extent (no more than a few hundred meters) and a cloud top height (CTH) controlled by the PBL depth but spread out over tens to hundreds of kilometers (Wood, 2012) either homogeneously or heterogeneously (open-cell). In between these two distinct regimes, various transitioning clouds may form (Albrecht et al., 2019; Teixeira et al., 2011), and the most frequent are broken $\mathrm{Sc}$ and transition $\mathrm{Sc}-\mathrm{Cu}$, which is composed of $\mathrm{Cu}$ under Sc (Albrecht et al., 2019; Rauber et al., 2007) and $\mathrm{Cu}$ with stratiform outflow (Lamer et al., 2015; Nuijens et al., 2015b) (Fig. 1, second to fourth column, respectively). Clouds with a cloud base and a cloud top within and outside the lower free troposphere, respectively, are classified as deep $\mathrm{Cu}$ (Fig. 1, last column). Bearing the above facts in mind, we design the CASCCAD DA based on cloud height, vertical and horizontal cloud fraction, and horizontal continuity, which can be applied to both GOCCP instantaneous profiles and the CloudSat-CALIPSO level 2 geometrical profile product (referred to as RL-GeoProf).

GOCCP instantaneous profiles satisfy the criteria (i) and (ii) mentioned above. They use all $70 \mathrm{~m}$ large lidar shots every $333 \mathrm{~m}$ along track without horizontal averaging, which allows the detection of the geometrically sparsest shallow $\mathrm{Cu}$, besides the more horizontally extended Sc, over a relatively extended time period (from June 2006 to 2017, while CALIPSO is still operating as of April 2019). This decadal 


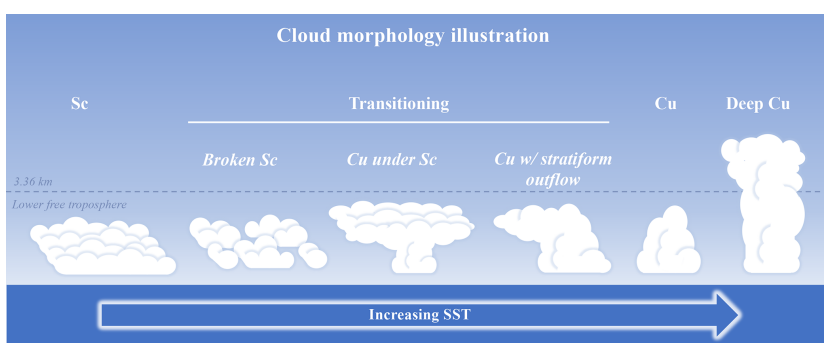

Figure 1. Illustration representing the different cloud morphologies used in this study. The blue dashed line denotes the upper limit of the low-level clouds following the GOCCP definition $(3.36 \mathrm{~km})$. Note that the deep $\mathrm{Cu}$ type is not a low cloud but either a mid- or high-level cloud.

dataset makes it possible to analyze climatological values of $\mathrm{Cu}$ and $\mathrm{Sc}$ cloud fraction and their relationships to environmental parameters. However, as the lidar penetrates within cloudy layers, the signal eventually attenuates completely for optical thickness greater than 3 to 5 . Therefore, it is not always possible to observe the full troposphere with a spaceborne lidar, which may cause differences in satellitebased cloud climatologies obtained from different instruments (Kikuchi et al., 2017; Thorsen et al., 2013). In these instances - i.e., in deep convective clouds or in the storm tracks - the CPR capability complements cloud profiles beneath the height at which the lidar attenuates, although the CPR clutter prevents using CloudSat data below $\sim 1000 \mathrm{~m}$. Unfortunately, the RL-GeoProf product is only available for a short period of time $(\sim 4.5$ years $)$ due to the severe anomaly of April 2011, which is why CloudSat-CALIPSO observations satisfy (i) but only partially (ii). Note that the release R05 of RL-GeoProf came out after the submission of the original manuscript (late May 2019), which includes data after April 2011. However, these are for daytime only and substantial periods of time are still missing (e.g., May 2011 through May 2012 and the whole year of 2014), which makes it difficult to compute a consistent climatology and derive statistical relationships between clouds and environmental variables. Additionally, the differences between CASCCAD using RL-GeoProf R04 and R05 are very small in the case studies of Sect. 4.1 (see Figs. S2-S5). There is a small decrease of the overall cloud fraction ( 76.3 vs. $75.8 \%, 37.2$ vs. $35.2 \%$, 15.9 vs. $16 \%$, and 80.8 vs. $77.2 \%$ for R04 and R05, respectively), which affects mostly the $\mathrm{Cu}$ cloud fraction. Since the change is almost negligible, we decided not to update the global statistics with the R05 version for the sake of computational, spatial and temporal resources.

\subsection{First criterion of the discrimination algorithm: the cloud top height}

As mentioned above, four main criteria - represented by different colors in Fig. 2 - are used in the DA to separate Sc from $\mathrm{Cu}$ clouds and to characterize the various transitioning clouds presented in Fig. 2: the CTH, the horizontal cloud fraction $(\mathrm{HCF})$, the vertical profiles of cloud fraction (VCF) and the horizontal continuity test. Note that the sensitivity to these criteria is later tested in Sect. 4.1. The first step of the DA depends on the height of the cloud top (Fig. 2, first column, in gray). Because trade $\mathrm{Cu}$ and $\mathrm{Sc}$ are low clouds, their $\mathrm{CTH}$ must be within the lower free troposphere, which is defined as $3.36 \mathrm{~km}$ in GOCCP (approximately equivalent to the $680 \mathrm{hPa}$ definition of Rossow and Schiffer, 1999). Furthermore, since Sc clouds cap the PBL, their CTH is typically lower than the PBL height over the main Sc deck areas, i.e., $\sim 2 \mathrm{~km}$ (Albrecht et al., 1995; Bretherton et al., 2010; Garay et al., 2008; Wood, 2012; Zhou et al., 2015; Zuidema et al., 2009). Therefore, all cloud layers - i.e., a vertically contiguous group of cloudy $480 \mathrm{~m}$ pixels - with a cloud top higher than $1.92 \mathrm{~km}$, which is the closest $480 \mathrm{~m}$ GOCCP level to $2 \mathrm{~km}$, are diagnosed as $\mathrm{Cu}$ type. We remind the reader that the sensitivity of the algorithm to this criterion, as well as the other criteria, is tested in Sect. 4.1.

\subsection{Second criterion: the horizontal cloud fraction}

The remaining clouds are passed to the second step of the DA (Fig. 2, second column, in orange), which computes the HCF either centered around the lidar profiles (CHCF) or using forward (FHCF) or backward profiles (BHCF) as shown in Fig. 3. These three HCFs ensure capturing the full horizontal extent of the cloud layer regardless of whether the lidar probes toward the edge or the center of the layer while remaining more computationally efficient than treating clouds by contiguous horizontal clusters. For example, the CHCF is $100 \%$ in the specific case of Fig. 3a, whereas FHCF and BHCF are about $50 \%$. Should the first lidar profile be at the beginning of the cloud, the centered, forward and backward HCF would be about 53\%, $100 \%$ and $7 \%$ (Fig. 3b). Additionally, the HCFs are computed over four different length scales, $10,20,40$ and $80 \mathrm{~km}$, to characterize various cloud scenarios: open-cell and closed-cell Sc (Wood, 2012), as well as different $\mathrm{Cu}$ organizations in $\mathrm{Sc}-\mathrm{Cu}$ transition clouds (Albrecht et al., 2019; Lamer et al., 2015; Rauber et al., 2007; Teixeira et al., 2011). The larger 40-80 km scales permit a clear distinction between the two types of clouds since Sc clouds typically cover vast areas compared to morefractionated trade-Cu clouds. Figure $4 \mathrm{c}$ and d show the probability density function (PDF) of the 40 and $80 \mathrm{~km}$ CHCFs, respectively, for typical $\mathrm{Cu}$ (light blue bars) and $\mathrm{Sc}$ (light red bars) cases extracted from day and night CALIPSO orbits over the tropics $\left(35^{\circ} \mathrm{S} / \mathrm{N}\right.$, eight orbit segments in total). These results confirm a rather clear separation, marked by purple lines, between the two populations for CHCFs. Although some slight overlap is visible, it disappears when the 40 and $80 \mathrm{~km} \mathrm{CHCFs}$ are run together (not shown). However, in regions of open-cell Sc and $\mathrm{Sc}-\mathrm{Cu}$ transition, the overlap may be larger (Fig. S6), and additional tests are needed to 
Flow diagram of the $\mathrm{Cu}-\mathrm{Sc}$ discrimination

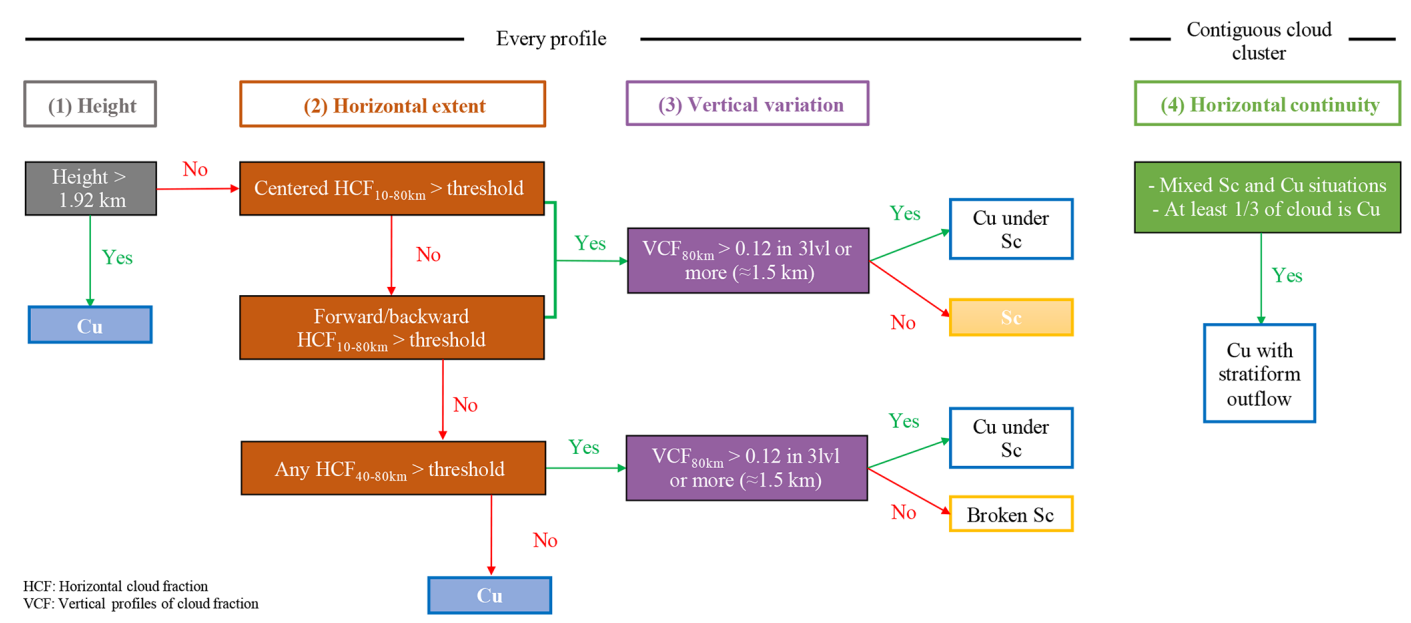

Figure 2. Flow diagram of the algorithm that performs the $\mathrm{Sc}-\mathrm{Cu}$ discrimination. The gray, orange, purple and green colors represent the different steps of the discrimination algorithm to separate $\mathrm{Sc}$, broken $\mathrm{Sc}, \mathrm{Cu}, \mathrm{Cu}$ under $\mathrm{Sc}$ and $\mathrm{Cu}$ with stratiform outflow clouds: height, horizontal extent, vertical extent and horizontal continuity, respectively. The choice of HCF thresholds is discussed in Sect. 3.3 and their values are shown in Fig. 4. The VCF threshold (0.12) and the horizontal continuity test are also explained in Sect. 3.4 and further used in Fig. 5. Note that the steps 1 to 3 are applied to every profile while the step 4 is only applied to contiguous cloud clusters.

determine the type of clouds, i.e., Sc, broken $\mathrm{Sc}, \mathrm{Cu}$ under $\mathrm{Sc}, \mathrm{Cu}$ with stratiform outflow or $\mathrm{Cu}$. In those instances, the 10 and $20 \mathrm{~km}$ CHCFs help further distinguish Sc from the other clouds (Fig. 4a and b). Finally, note that when all $480 \mathrm{~m}$ pixels below $1.92 \mathrm{~km}$ are fully attenuated (4 pixels), the profile is excluded from the HCF computation - consistent with what is done in the GOCCP product for cloud fraction computations - because we do not know whether these pixels are clear or cloudy.

\subsection{Third criterion: the vertical profiles of cloud fraction}

The third step of the DA (which comes into play only if the first two criteria have ruled out a pure $\mathrm{Cu}$ cloud) utilizes the VCF to capture the $\mathrm{Cu}$ under $\mathrm{Sc}$ and broken Sc clouds (Fig. 2, third column, in purple). In our study, the vertical profile of cloud fraction (VCF, sometimes referred to as the vertical distribution of cloud fraction or cloud fraction profiles in previous literature) corresponds to the cloud fraction computed over $80 \mathrm{~km}$ along track at a particular level; in other words, it represents how often a cloud is encountered over $80 \mathrm{~km}$ in the horizontal direction at a particular level. Since Sc clouds are relatively shallow - no more than a few hundred meters (Wood, 2012) - any cloud layer with a substantial VCF over three levels or more (vertical extension greater than $1.44 \mathrm{~km}$ ) is corrected from $\mathrm{Sc}$ to $\mathrm{Cu}$ under $\mathrm{Sc}$ while the rest remain diagnosed as Sc (Fig. 5a). The VCF threshold $(=0.12)$ is defined as approximately 2 times the standard deviation of the PDF of the $40 \mathrm{~km}$ CHCF computed using each of the seven first levels ( 0 to $3.36 \mathrm{~km})$ in typical $\mathrm{Cu}$ regions. Note that because the CloudSat-CALIPSO vertical cloud fraction is less

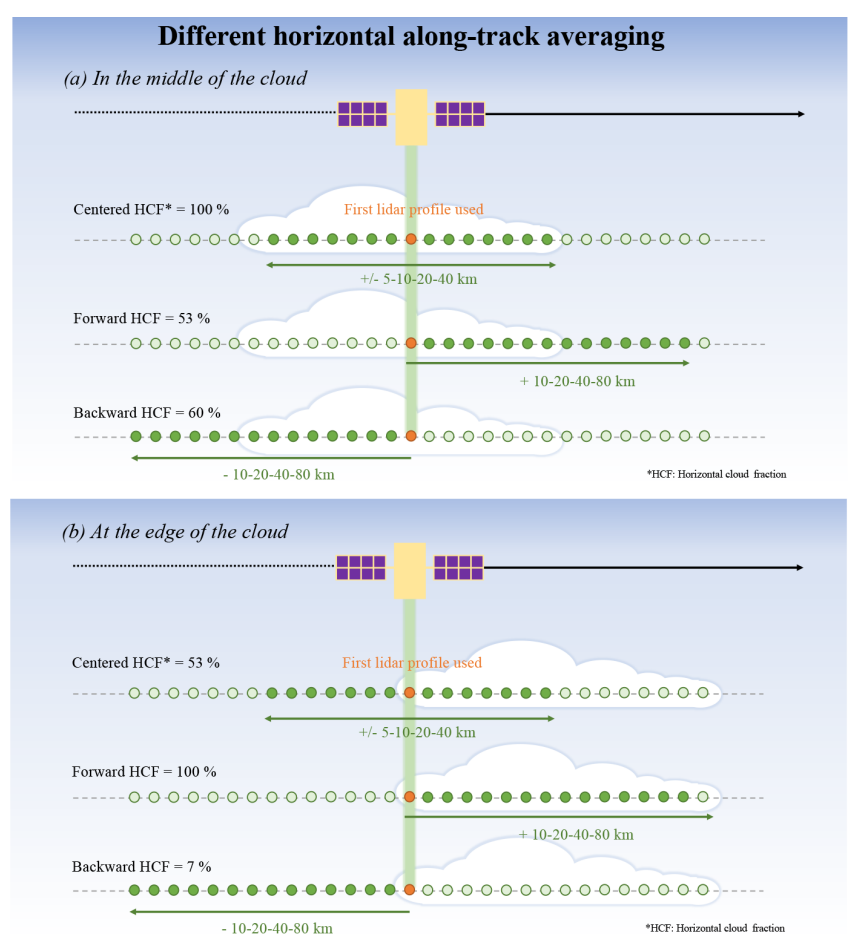

Figure 3. Illustration of the horizontal along-track averaging that is used by the DA to compute the horizontal cloud fraction (HCF): (a) the lidar beam is in the middle of the cloud and (b) the lidar beam is at the edge of the cloud. The dark-green circles correspond to the profiles used in the different horizontal averaging scenarios (centered, forward or backward). 

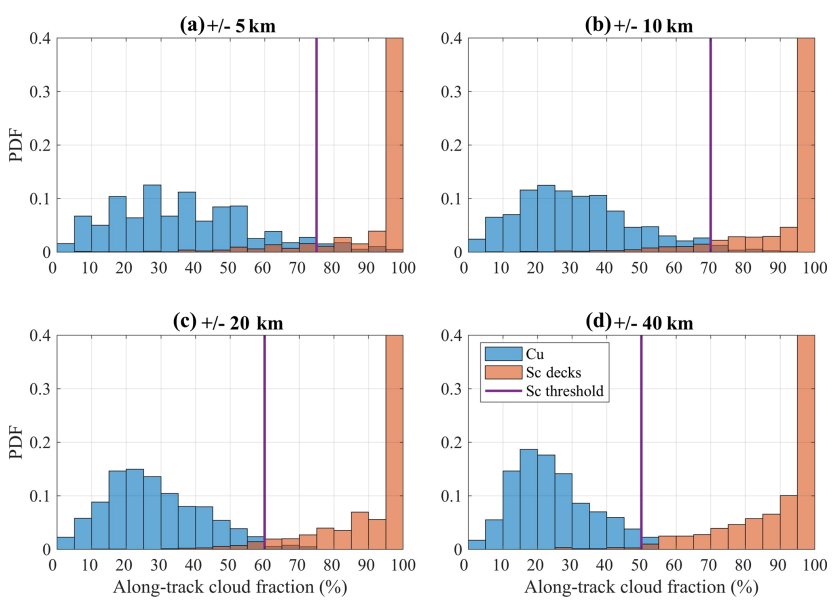

Figure 4. PDF of the different along-track $\mathrm{CHCF}$ for $\mathrm{Cu}$ (blue) and $\mathrm{Sc}$ (light red) typical regions computed from eight orbit segments. The thresholds are represented in purple, at approximately the overlap of the two distributions.

affected by attenuation, we defined a larger VCF threshold $(=0.3)$ for the RL-GeoProf CASCCAD version. Finally, this VCF test is also applied to any cloud layer that passes the 40 and $80 \mathrm{~km}$ HCFs thresholds, regardless of their 10 and $20 \mathrm{~km}$ HCFs. In these cases, the cloud type is diagnosed as $\mathrm{Cu}$ under Sc if the VCF threshold is met, otherwise the cloud layer is diagnosed as broken Sc.

\subsection{Fourth criterion: the horizontal continuity test}

Once the cloud type is determined using the first three criteria, it is applied vertically to the whole cloudy layer. While the DA takes into account the horizontal extent of a cloud system via the computation of HCFs (including possible clear sky profiles), it does not track horizontally contiguous clusters of clouds (without clear sky profiles). As a result, in $\mathrm{Cu}$ and transition $\mathrm{Sc}-\mathrm{Cu}$ cases, the same horizontally contiguous cloud layer may be diagnosed as both Sc-type (Sc and/or broken $\mathrm{Sc}$ ) and $\mathrm{Cu}$ (Fig. 5b), which is more likely a $\mathrm{Cu}$ with a stratiform outflow (Lamer et al., 2015). To capture these particular clouds, we apply a horizontal continuity test (Fig. 2, fourth column, in green), which first detects a horizontally contiguous cluster of clouds and then turns the non$\mathrm{Cu}$ part (i.e., Sc, broken $\mathrm{Sc}$ or $\mathrm{Cu}$ under $\mathrm{Sc}$ ) into a $\mathrm{Cu}$ with stratiform outflow if one-third of the cluster is diagnosed as $\mathrm{Cu}$ type. We chose this arbitrary threshold because, on average, the fraction of the $\mathrm{Cu}$ that expands further aloft (geometrically thicker) is typically smaller than that near the lifting condensation level (LCL; Nuijens et al., 2015a) or that detrained near the trade-wind inversion (Nuijens et al., 2015a; Lamer et al., 2015).

\section{Results}

\subsection{Case studies}

To assess our CASCCAD DA, we analyze a series of three typical case studies: trade cumulus, stratocumulus and stratocumulus-cumulus transitioning clouds. First, we investigate the sensitivity of the DA to some of the criteria presented in Sect. 3 using GOCCP observations: the HCF (more or less conservative), CTH (one level higher) and $\mathrm{VCF}$ (smaller threshold, divided by 2) thresholds and the horizontal continuity test (turned off). We then compare the results of the standard DA applied separately to GOCCP and RLGeoProf against the 2BCCL cloud types - for the same case studies - and utilize the collocated MODIS reflectance to provide a broader context of the cloud scene.

\subsubsection{Stratocumulus case}

Figure 6 shows the sensitivity of the GOCCP Sc-Cu Mask (Fig. 6b) to the different parameters used in the DA (Fig. 6cg) for a daytime orbit segment off the coast of California during summer (see Fig. S7 for the exact location). The refined CALIPSO Science Team (CALIPSO-ST) cloud mask $(\Delta z=30 \mathrm{~m}$; Vaughan et al., 2009) helps us get a better sense of the cloud geometrical thickness where the lidar is not fully attenuated (Fig. 6a, black color). Additionally, the MODIS true reflectance image confirms the presence of stratiform layers of clouds throughout the CALIPSO-CloudSat path (Fig. 7d). Except for the lower VCF parameters, which reduce the along-track $\mathrm{Sc} \mathrm{CF}\left(\mathrm{HCF}_{\mathrm{Sc}}\right)$ by $5.6 \%$ (absolute value, Fig. $6 \mathrm{c}$ ), the $\mathrm{HCF}_{\mathrm{Sc}}$ is quite insensitive to the DA parameters $\left(\mathrm{HCF}_{\mathrm{Sc}}=69.4+0.3 /-1.3 \%\right)$. Reducing the VCF (Fig. 6c) turns the edges of the Sc decks into transitioning $\mathrm{Sc}-\mathrm{Cu}$ clouds (around 16 and $20^{\circ} \mathrm{N}$ ). However, changing the HCF thresholds has a limited effect on the $\mathrm{HCF}_{\mathrm{Sc}}$ in this particular case (Fig. $6 f$ and g).

GOCCP and RL-GeoProf have a similar $\mathrm{HCF}_{\mathrm{Sc}}$ while that of the 2BCCL product is smaller along with its total $\mathrm{HCF}$ (Fig. 7). The substantial difference between RL-GeoProf and 2BCCL total HCFs is mostly due to differences in lidar cloud fraction treatment. The lidar cloud fraction from RL-GeoProf comes from the CALIPSO $5 \mathrm{~km}$ VFM mask, whereas that of $2 \mathrm{BCCL}$ comes from the Lidar-AUX product (Wang et al., 2013).

\subsubsection{Cumulus case}

As for the Sc case, the along-track $\mathrm{Cu} \mathrm{CF}\left(\mathrm{HCF}_{\mathrm{Cu}}\right)$ is weakly sensitive to variations of the different DA parameters (Fig. 8, $\left.\mathrm{HCF}_{\mathrm{Cu}}=23.6+1.1 /-1.5 \%\right)$. The most sensitive parameter is the horizontal continuity (Fig. 8e). When activated, it converts most of the large $\mathrm{Cu}$ between 20 and $18^{\circ} \mathrm{S}$ from $\mathrm{Sc}$ to $\mathrm{Cu}$ with stratiform outflow, although its southernmost edge remains likely incorrectly diagnosed as Sc. Most of the other cloudy features are diagnosed as $\mathrm{Cu}$ except for the cloudy 
(a) $\mathrm{Cu}$ under $\mathrm{Sc}$
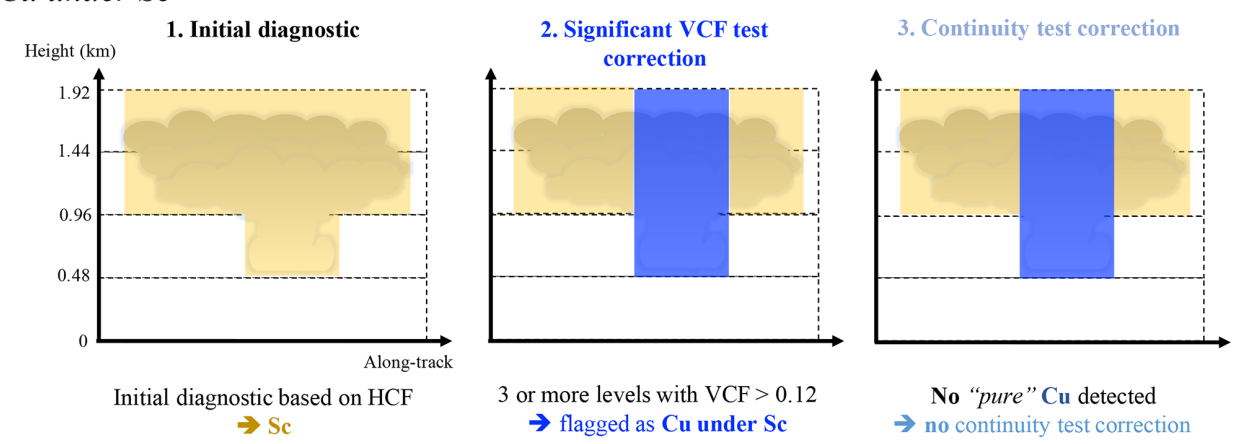

(b) Cu with stratiform outflow
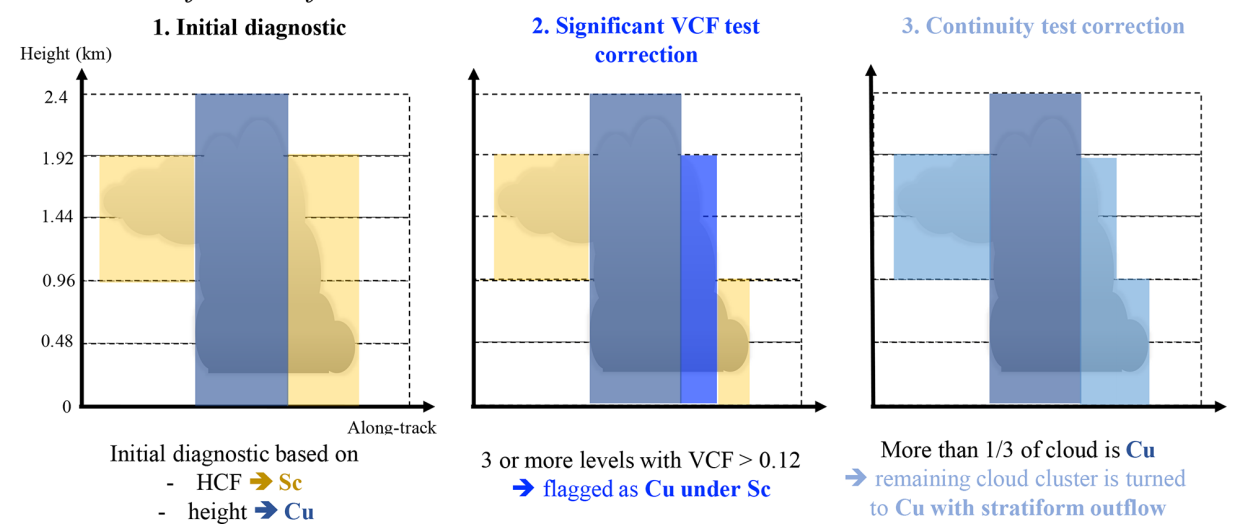

Figure 5. Illustration of the $\mathrm{Cu}$ and $\mathrm{Sc}$ mixed situations using additional diagnostics in the DA: (a) $\mathrm{Cu}$ under $\mathrm{Sc}$ and (b) Cu with stratiform outflow. After the DA diagnoses (1) an initial cloud type, the additional (2) significant VCF variability test and (3) horizontal continuity correction are applied to contiguous cloud clusters (see details in Sect. 3.4 and 3.5).

layer located between 31 and $29^{\circ} \mathrm{S}$, which seems to be stratiform judging from its geometrical thickness (Fig. 8a) and reflectance (Fig. 9d).

Here again, both GOCCP and RL-GeoProf diagnose similar Sc and $\mathrm{Cu} \mathrm{HCF}$ although the DA fully captures the aforementioned large $\mathrm{Cu}$ only when it is used with RL-GeoProf observations (Fig. 9b). Unlike the Sc case, GOCCP and RLGeoProf disagree substantially with 2BCCL. For example, several cloud clusters are diagnosed as Sc by the 2BCCL algorithm although their geometrical thickness is larger than $1.5 \mathrm{~km}$ (Fig. 9c, around 34,19 and $12^{\circ} \mathrm{S}$ ), making it very unlikely that these clusters are actual Sc. As a result, the $\mathrm{HCF}_{\mathrm{Sc}}(17.2 \%)$ is as large as the $\mathrm{HCF}_{\mathrm{Cu}}(18.3 \%)$ and approximately 3 times larger than that of GOCCP and RLGeoProf. An additional $\mathrm{Cu}$ case, in the trade-dominated NW Atlantic, confirms the ability of the DA to correctly diagnose a field of purely $\mathrm{Cu}$ clouds with no Sc (Fig. 10a and b). Contrary to Fig. 9c, the 2BCCL product does not detect Sctype clouds (Fig. $10 \mathrm{c}, \mathrm{HCF}_{\mathrm{Sc}}=0 \%$ ) and even underestimates the $\mathrm{Cu}$ cloud fraction $\left(\mathrm{HCF}_{\mathrm{Cu}}=10 \%\right)$ compared to GOCCP and RL-GeoProf $\left(\mathrm{HCF}_{\mathrm{Cu}}=19.5 \%\right.$ and $15.9 \%$, respectively). This case also highlights one of two notable differences between the GOCCP and RL-GeoProf CASCCAD datasets: the latter misses a significant amount of cloud below $1 \mathrm{~km}$ altitude in scattered cumulus environments, presumably due to a combination of the radar surface clutter limitation and the lidar $\mathrm{CF}_{\text {lidar }}$ threshold used to diagnose a pixel as cloudy $\left(\mathrm{CF}_{\text {lidar }}=0.5\right.$, cf Sect. 2.2).

\subsubsection{Cumulus and open-cell stratocumulus case}

The last case study extends from the subtropics to the extratropics. Such a location allows us to characterize transitioning $\mathrm{Sc}-\mathrm{Cu}$ cases, which includes Sc, open-Sc and the different Cu-type clouds (Fig. 11). A visual inspection of the CTH variation from the CALIPSO VFM (Fig. 11a) suggests that this orbit segment contains three distinct clusters of clouds: $\mathrm{Sc}$ from 55 to $43^{\circ} \mathrm{S}$ and from 25 to $20^{\circ} \mathrm{S}$ and $\mathrm{Cu}$ in between. These three distinct layers are quite well captured by the DA although the DA is more sensitive to changes in the parameters than in the other cases. The most sensitive parameters are the VCF and HCF thresholds. Reducing the VCF threshold (Fig. 11c) turns $7.6 \%$ of the $\mathrm{Sc}$ into $\mathrm{Cu}$ (absolute value) mostly poleward of $43^{\circ} \mathrm{S}$ because the boundary layer height decreases, causing multiple levels to be cloudy and subsequently diagnosed as $\mathrm{Cu}$. Choosing smaller HCF thresholds 


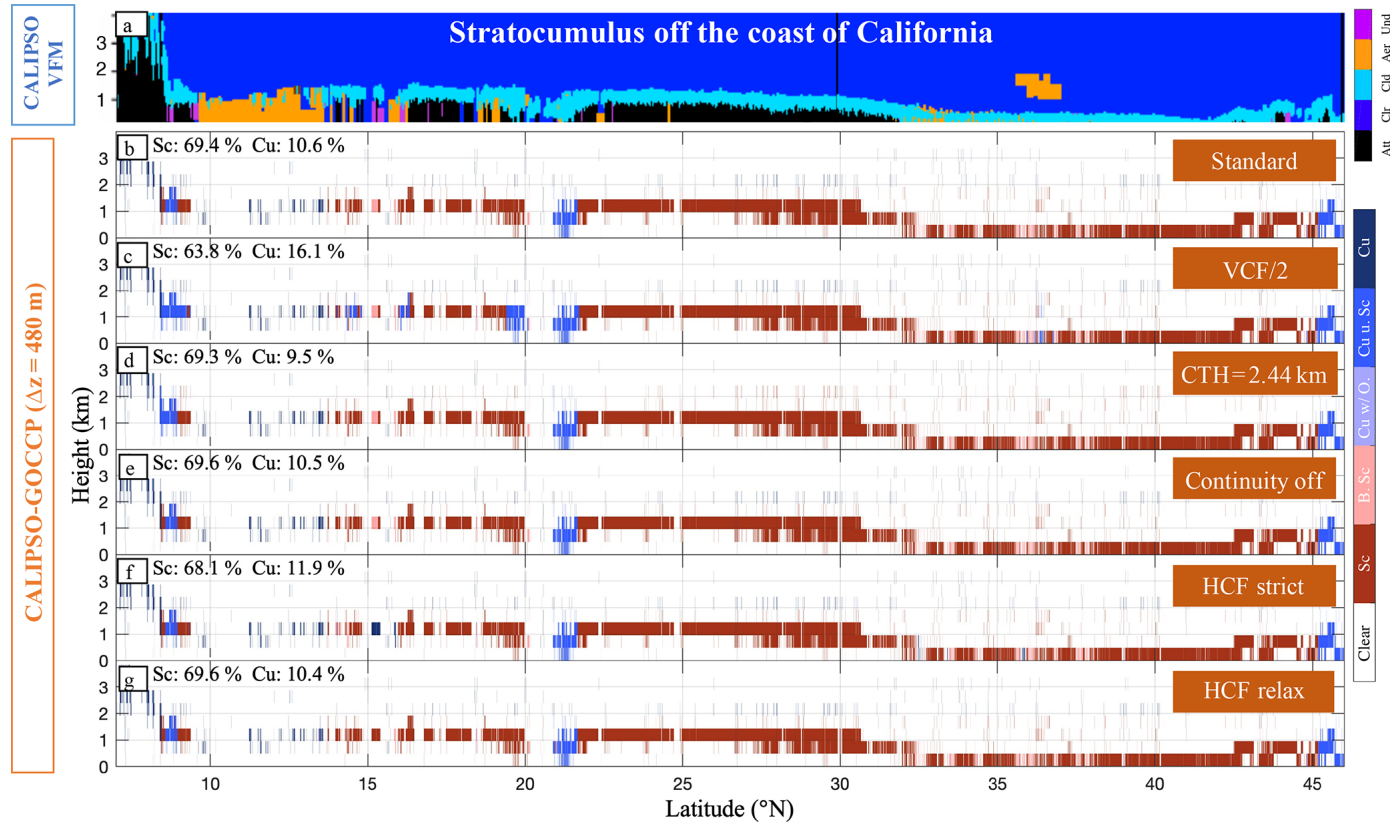

Figure 6. Daytime orbit segment off the coast of California ( $\sim 8$ to $46^{\circ} \mathrm{N}, 8$ July 2008 21:47:30) showing a typical stratocumulus case. (a) VFM CALIPSO-ST at $30 \mathrm{~m}$ vertical resolution; (b) to (g) sensitivity of the GOCCP Sc-Cu mask to different DA parameters: (b) the VCF threshold is divided by 2, (c) the CTH threshold is elevated from 1.92 to $2.4 \mathrm{~km}$, (d) standard DA parameters, (e) the continuity test is turned off, (f) the 10 and $20 \mathrm{~km}$ HCF thresholds are more conservative (i.e., increased by 0.1 , absolute value), and (g) the 10 and $20 \mathrm{~km}$ HCF thresholds are less conservative (i.e., decreased by 0.1, absolute value). The HCF of Sc-dominated (including broken Sc) and Cudominated (including $\mathrm{Cu}$ under $\mathrm{Sc}$ and $\mathrm{Cu}$ with stratiform outflow) clouds are given in each subplot (top left corner). Reddish and bluish pixels correspond to Sc-dominated and $\mathrm{Cu}$-dominated type of clouds, respectively. From the top to the bottom, the VFM color bar's labels correspond to undetermined, aerosol, cloudy, clear and fully attenuated pixels. From the top to the bottom, the GOCCP Sc-Cu mask color bar's labels correspond to cumulus, $\mathrm{Cu}$ under $\mathrm{Sc}, \mathrm{Cu}$ with stratiform outflow, broken $\mathrm{Sc}$, stratocumulus and clear pixels.

(Fig. 11g) increases the Sc amount by $5.2 \%$ (absolute value). This converts the few $\mathrm{Cu}$ poleward $43^{\circ} \mathrm{S}$ into $\mathrm{Sc}$ as well as some $\mathrm{Cu}$ around $24^{\circ} \mathrm{S}$, which could very well be "true" Sc.

The three clusters of clouds are also well captured in the RL-GeoProf dataset, which detects somewhat a little more $\mathrm{Cu}$ and $\mathrm{Sc}$ than GOCCP, making the total HCF larger as well (Fig. 12), possibly due to the $\mathrm{CF}_{\text {lidar }}$ threshold, which may cause an overestimation of the cloud fraction. Also note that the additional $\mathrm{Cu}$-type clouds detected by the RL-GeoProf product are mostly classified as $\mathrm{Cu}$ with stratiform outflow. On the contrary, the 2BCCL product diagnoses nearly 2 times more Sc than the CASCCAD datasets and 2 to 3 times less $\mathrm{Cu}$, while its total HCF is in between the two datasets.

\subsection{Statistical analysis}

\subsubsection{Maps}

In this section, we analyze climatological geographical distributions of $\mathrm{Sc}$ and $\mathrm{Cu}$ clouds for the three products presented before as well as for a subset of passive-sensor observations. For the CASCCAD datasets, we treat transitioning clouds as distinct cloud types and thus do not include them in the $\mathrm{Sc}$ and $\mathrm{Cu}$ cloud fractions to be discussed below, al- though one could easily include the broken Sc in the Sc cloud fraction and the $\mathrm{Cu}$ under $\mathrm{Sc}$ as well as the $\mathrm{Cu}$ with stratiform outflow in the $\mathrm{Cu}$ cloud fraction. The passive-sensor observations include the International Satellite Cloud Climatology Project (ISCCP, Rossow and Schiffer, 1999), the Moderate Resolution Imaging Spectroradiometer (MODIS, King et al., 2013) and the Multi-angle Imaging Spectroradiometer (MISR, Marchand et al., 2010) observations. In the passive remote sensing datasets, $\mathrm{Sc}$ and $\mathrm{Cu}$ are separated using a cloud top pressure (CTP) and cloud optical thickness (COT) diagram introduced by Rossow and Schiffer (1999): CTP must be larger than $680 \mathrm{hPa}$ for each type and COT smaller or larger than 3.6 for $\mathrm{Cu}$ and $\mathrm{Sc}$ clouds, respectively. There are advantages and disadvantages to each approach. In general, passive remote-sensing instruments provide better temporal and spatial sampling than active sensors, and the data products exist for a longer period of time. On the other hand, passive sensors can have difficulty identifying cloud top altitude, especially in multilayer situations, relative to active sensors. For our purposes, we note that the COT-based method has been shown to misclassify $\mathrm{Cu}$ and $\mathrm{Sc}$ that have moderate optical thickness (e.g., Pincus et al., 1999). In addition, Mace and Wrenn (2013) showed that, except for thin cirrus and Sc cloud types, the COT-derived cloud types are 


\section{Stratocumulus off the coast of California}
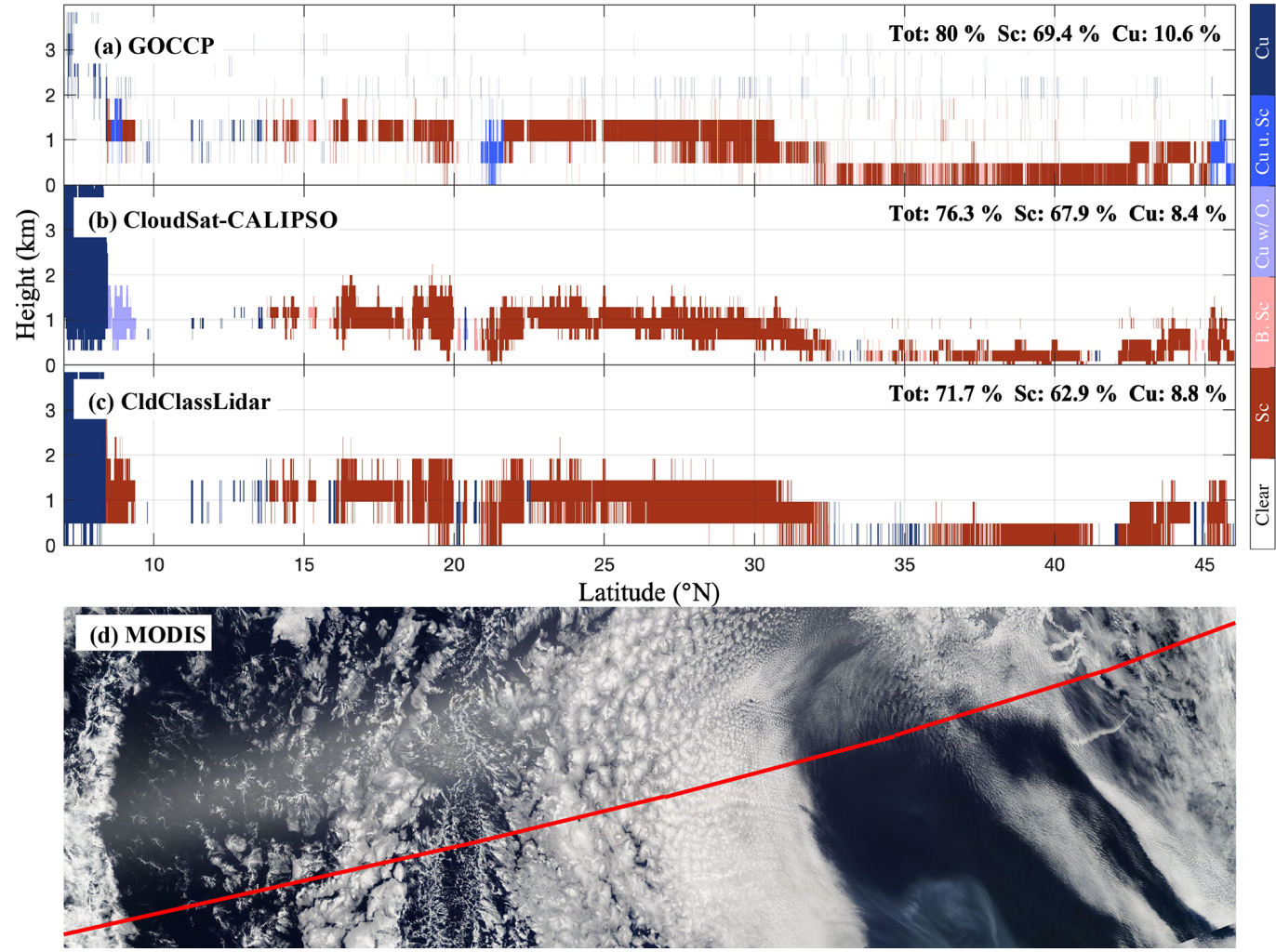

Figure 7. Same stratocumulus case study as in Fig. 5 but for (a) the standard GOCCP Sc-Cu mask (same as Fig. 5b), (b) the RL-GeoProf $\mathrm{Sc}-\mathrm{Cu}$ mask, (c) 2BCCL cloud-type mask and (d) MODIS true reflectance. The red line corresponds to the CALIPSO-CloudSat overpass.

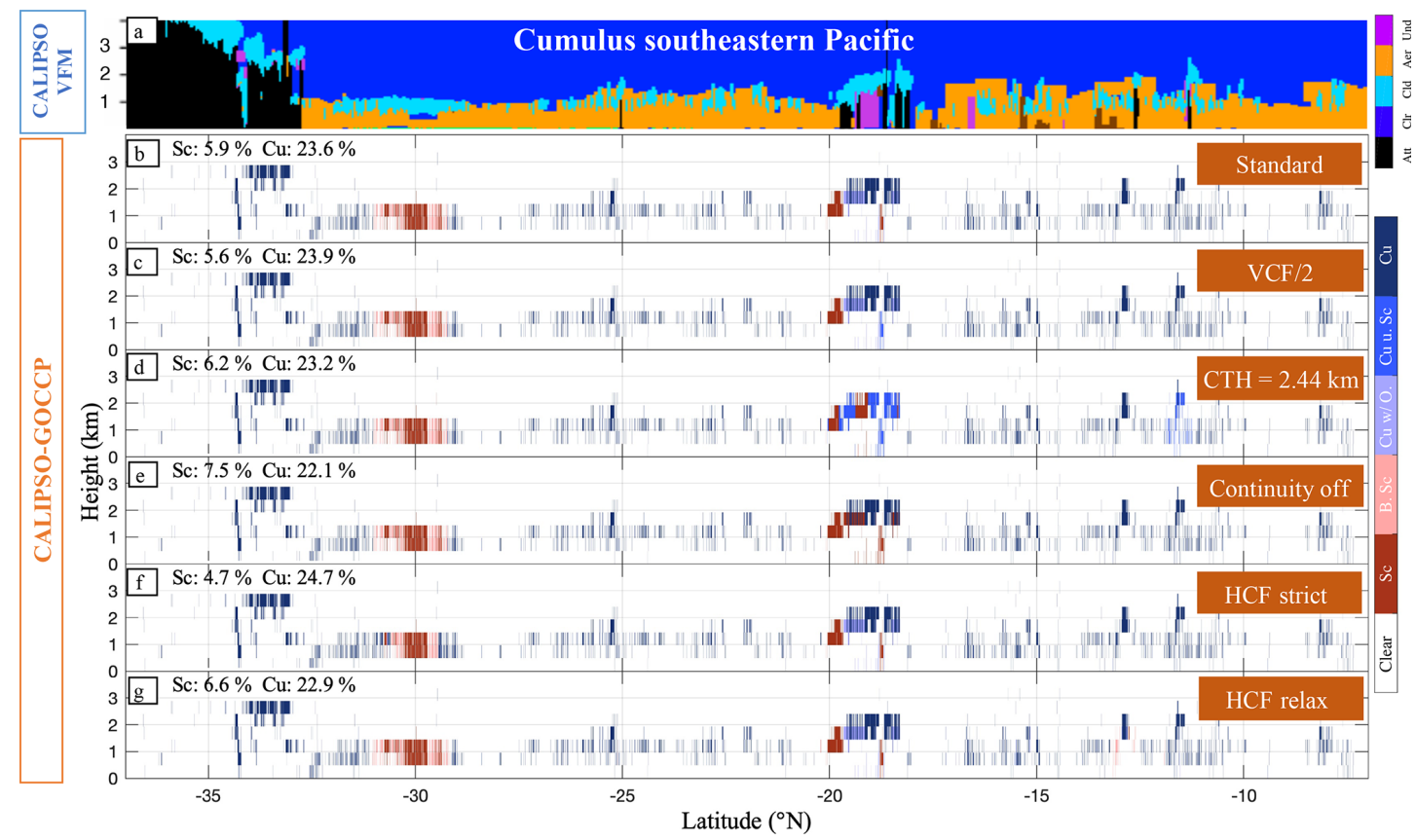

Figure 8. Same as Fig. 5 but for a typical cumulus case in the southeastern Pacific ( $\sim 37$ to $8^{\circ}$ S, 8 July 2008 21:47:30, daytime). 


\section{Cumulus southeastern Pacific}
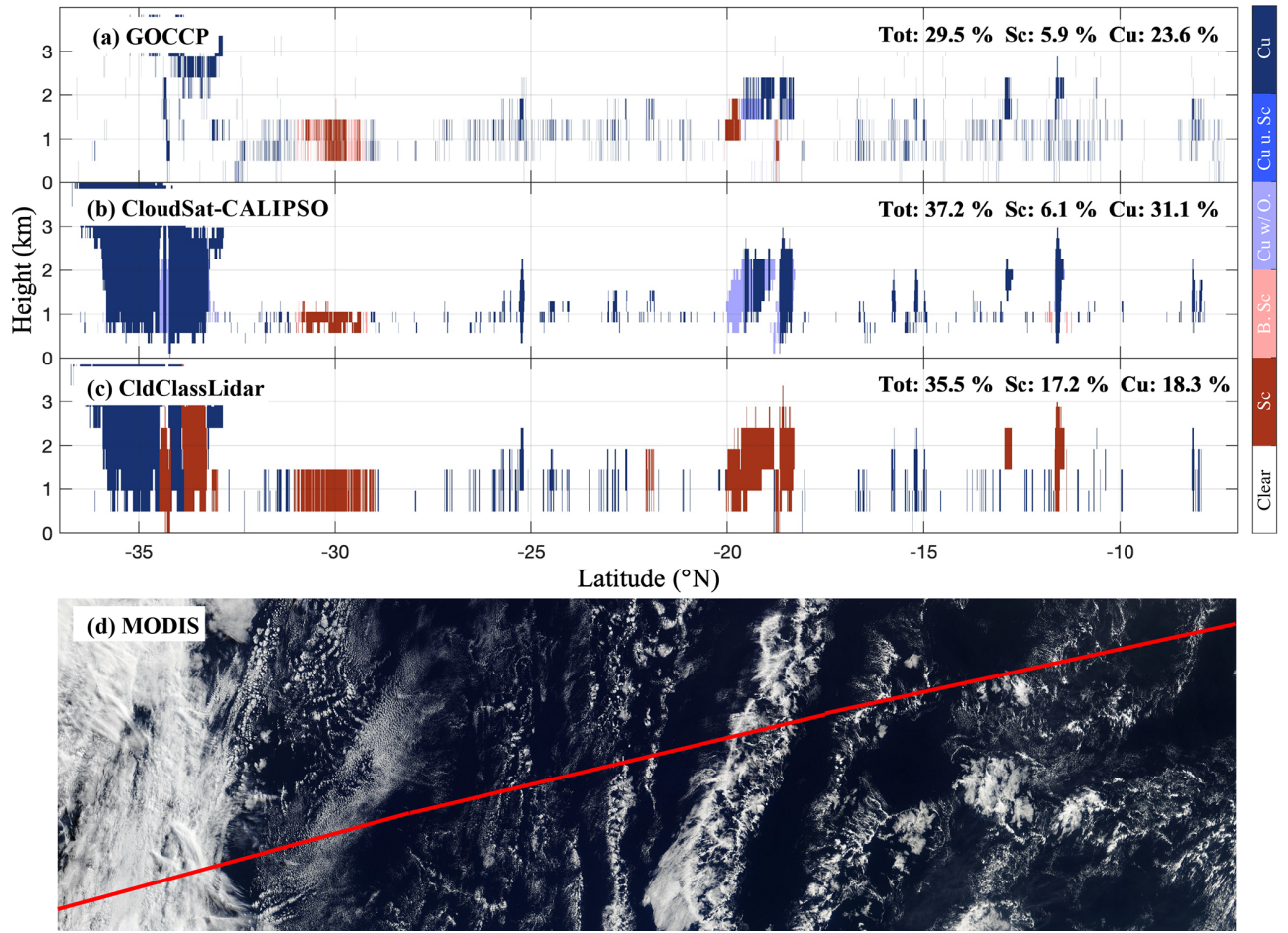

Figure 9. Same as Fig. 6 but for a typical cumulus case in the southeastern Pacific ( $\sim 37$ to $8^{\circ}$ S, 8 July 2008 21:47:30, daytime).

\section{Cumulus Barbados}
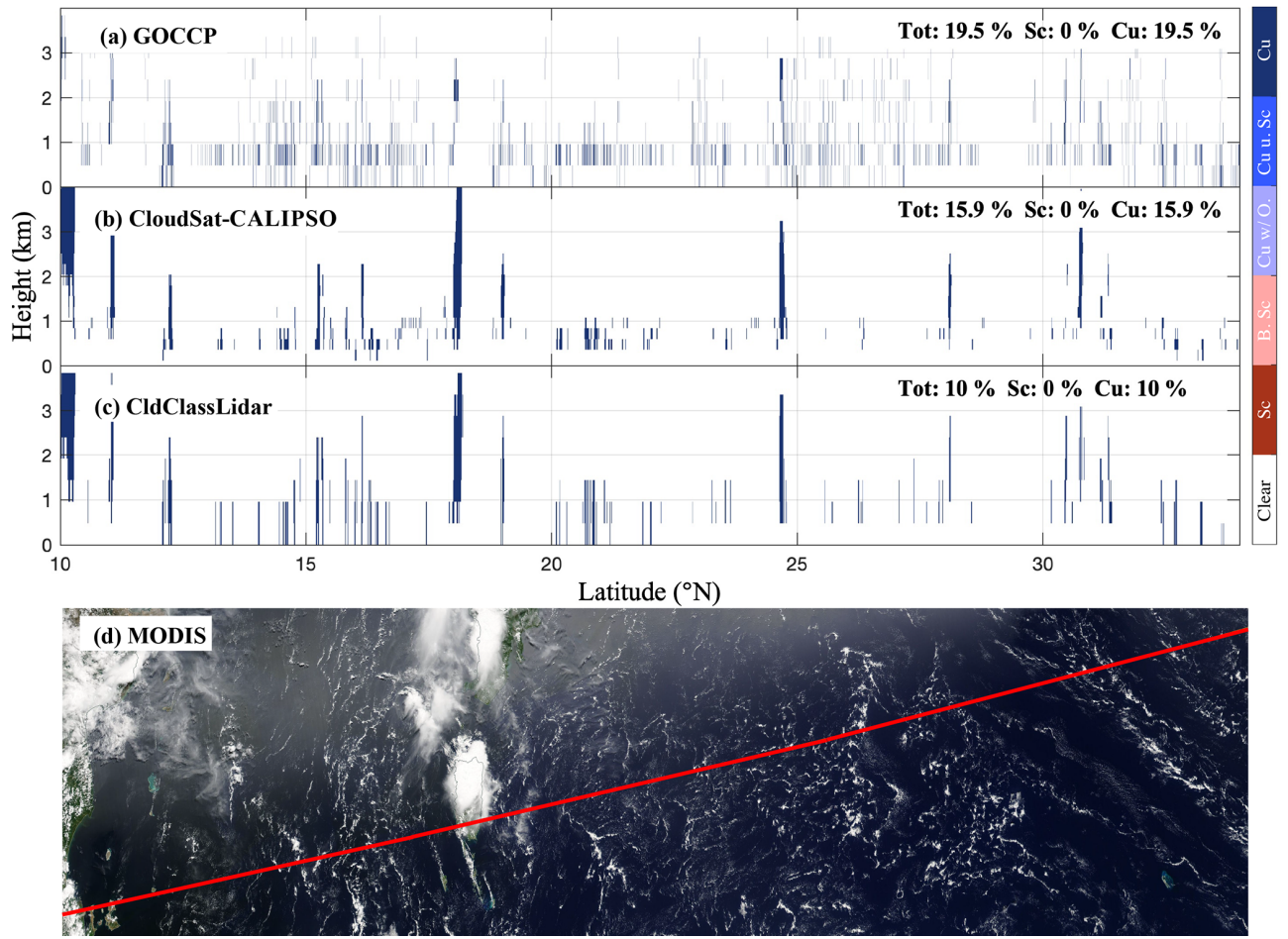

Figure 10. Same as Fig. 8 but for another cumulus case overpassing Barbados ( $\sim 10$ to $35^{\circ}$ N, 9 July 2008 17:34:08 daytime). 


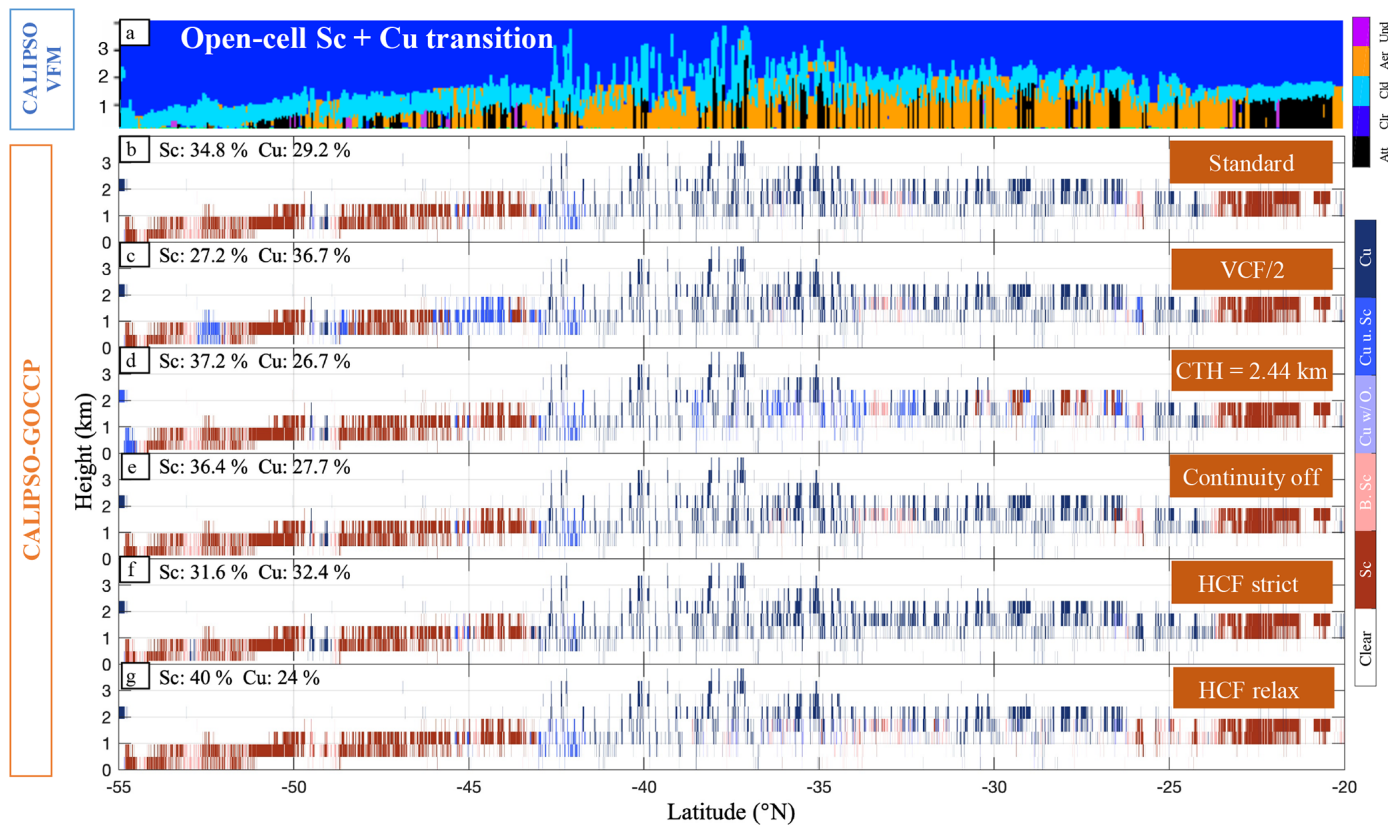

Figure 11. Same as Fig. 5 but for a typical open-cell Sc to Cu transitioning case overlapping the southeastern Pacific and the Southern Ocean ( $\sim 55$ to $20^{\circ} \mathrm{S}, 14$ July 2008 21:10:19, daytime).

mostly mixtures of different cloud types in two regions of the eastern Pacific. However, passive-sensor estimates of Sc and $\mathrm{Cu}$ provide a broader context and help us emphasize the added value of new $\mathrm{Sc}-\mathrm{Cu}$ discrimination methods based on active-sensor satellites.

Overall, all products identify the large cloud fraction in the tropical and subtropical stratocumulus areas, off the west coast of the continents (Fig. 13, top row), quite well. RLGeoProf and 2BCCL products detect the largest low-level cloud fraction (Fig. 14, zonal and global mean, top row), although they might overestimate the fractionated clouds (e.g., $\mathrm{Cu}$ ). Unlike the passive-sensor products - based solely on the CTP and COT - the active-sensor products do not detect a significant amount of $\mathrm{Cu}$ off the west coasts of the continents compared to the large Sc cloud fraction, which ranges from $50 \%$ off the coast of Australia up to $85 \%$ in the heart of the deck off the coast of Peru in both GOCCP and RL-GeoProf (Fig. 13, third row). These results are somewhat different from a previous analysis in which the $\mathrm{Sc}$ cloud fraction ranges from $40 \%$ to $60 \%$ over the Sc deck areas (Wood, 2012). On the contrary, the CASCCAD products place a substantial amount of $\mathrm{Cu}$ clouds west of the $\mathrm{Sc}$ decks (up to $40 \%$ ) and in the trade-wind regions (between $20 \%$ and $30 \%$ ), similar to MISR observations (Fig. 13, third row), which is more sensitive to fractionated clouds than ISCCP and MODIS, while 2BCCL only classifies a small amount of $\mathrm{Cu}$ clouds (between $10 \%$ and $15 \%$ ) in these regions. Here again our findings somewhat contradict earlier results retrieving Sc clouds $20 \%$ of the time in the tradewind regions (Wood, 2012). Besides the $\mathrm{Cu}$ and Sc cate- gories, the CASCCAD products have a third category referred to as transitional clouds (Fig. 13, fourth row), which is supposed to capture regions of transition between $\mathrm{Cu}$ and Sc clouds. As expected, these clouds are located between Sc decks and trade-wind regions and in the extratropics, where one could expect the two types of clouds to coexist. However, they represent a small part of the total low-cloud fraction in the tropics while it is larger in the extratropics (between $10 \%$ and $20 \%$, Fig. 14, fourth row), where both $\mathrm{Sc}$ and $\mathrm{Cu}$ types have a similar and substantial cloud fraction $(15 \%$ to $30 \%)$. As mentioned in the cumulus and open-cell stratocumulus case, RL-GeoProf CASCCAD classifies more transitioning clouds than its GOCCP counterpart. This is mainly due to the fact that RL-GeoProf contains larger cloud clusters than GOCCP, making the continuity test more efficient (e.g., the large $\mathrm{Cu}$ cloud cluster around $19^{\circ} \mathrm{S}$ in Fig. 9 and the $\mathrm{Cu}$ part of the open-cell and $\mathrm{Cu}$ case, Fig. 12), and also because RL-GeoProf is less affected by overlapping mid- and high-cloud attenuation and better captures the full vertical extent of low clouds. Finally, the ratio of Sc clouds to Sc and $\mathrm{Cu}$ clouds (transitioning clouds being excluded) documents the regions dominated by each type of clouds (Fig. 13, bottom row). Such information could be very useful to evaluate GCMs, which struggle to reproduce the $\mathrm{Sc}-\mathrm{Cu}$ transition (e.g., Teixeira et al., 2011). The CASCCAD products robustly describe the tropical open-ocean regions being almost exclusively dominated by $\mathrm{Cu}$ clouds while the oceans off the west coasts of the continents are mostly covered by Sc clouds. Such a picture is consistent with previous results from field campaigns, e.g., along the Global Energy and 
Water Cycle Experiment (GEWEX) Cloud System Studies (GCSS) Pacific Cross-section Intercomparison (GPCI) transect (e.g., Zhou et al., 2015), or ship-based observations in the southeastern Pacific (Garay et al., 2008) and groundbased data, e.g., over Barbados (e.g., Nuijens et al., 2015a). Finally, the CASCCAD products classify less Sc than the other products (Figs. 13 and 14, second row) in the extratropics and polar regions (poleward of $35^{\circ}$ ).

In the 2BCCL, MODIS and ISCCP products, most of the globe is dominated by Sc clouds, as opposed to the CASCCAD products and MISR, which depict the tropics dominated by $\mathrm{Cu}$ clouds and the extratropics by $\mathrm{Sc}$ clouds. The passive-sensor results suggest that the optical thickness does not permit a clear distinction between $\mathrm{Cu}$ and $\mathrm{Sc}$ clouds, in agreement with earlier studies (e.g., Pincus et al., 1999), although clustering analysis from passive-sensor observations may represent a better alternative (Tselioudis et al., 2013, their Fig. 3). To further investigate this statement, we classify GOCCP low clouds as a function of their opacity. The lowcloud-containing profiles that are diagnosed as opaque (i.e., no surface echo retrieved) have an optical thickness larger than approximately 3 (Guzman et al., 2017). This optical thickness is further used as a threshold to separate Sc (opaque clouds with $\mathrm{COT}>3$ ) from $\mathrm{Cu}$ clouds (thin clouds with COT $<3$ ), which is about the same optical thickness used in the passive sensor (i.e, $\mathrm{COT}=3.6$ ) to distinguish $\mathrm{Cu}$ and Sc clouds (i.e., COT $=3.6$ ). As for the passive-sensor satellite observations, this method does not allow a clear separation between the two cloud populations (Fig. S8), although the ratios of $\mathrm{Sc}$ to $\mathrm{Sc}$ and $\mathrm{Cu}$ derived from the two methods are well correlated $(\sim 0.65)$. However, it confirms that trade-wind regions have smaller opacity and therefore have a different radiative impact on surface and top-of-atmosphere (TOA) fluxes than more opaque Sc-dominated regions.

The newer clustering approaches, such as the ISCCP weather states (ISCCP-WS, Tselioudis et al., 2013) and MODIS cloud regimes (MODIS-CR, Oreopoulos et al., 2014), do not discriminate cloud types or even low cloud from middle and high clouds. Instead, they represent mixtures of cloud types although one cloud type is often prevalent in a given cluster. As such, it is not straightforward to directly compare them with the CASCCAD datasets. However, we believe that showing the results from the CR and WS approaches provides a broader context and additional information. For this reason, we analyze the ISCCP WS and MODIS CR observations against CASCCAD datasets in Fig. 15. The ISCCP-WS cloud fractions are obtained by multiplying the monthly relative frequency of occurrence (RFO) of WS7-8 for Cu and WS9-10-11 for Sc by the monthly total cloud fraction, based on Tselioudis et al. (2013). A similar method is applied for MODIS-CR cloud fractions with CR11 for $\mathrm{Cu}$ and CR7-8-9-10 for Sc, based on Oreopoulos et al. (2014). The clustering-derived datasets show an overall better agreement with CALIPSO and CloudSat-CALIPSO CASCCAD, particularly for the Sc regimes (Figs. 14 and 15).
In the tropics, the $\mathrm{Cu}$ regimes are better correlated with CALIPSO CASCCAD in terms of geographical distribution (from $r=0.26$ to 0.63 for ISCCP and $r=-0.02$ to 0.35 for MODIS), although MODIS underestimates their fraction while ISCCP overestimates it (likely due to mid- and highlevel clouds contained in WS7 and WS8). Note that CR12 is currently investigated to be further decomposed in CR12a-bc, and some of these sub-CRs could correspond to Cu-type regimes (Oreopoulos et al., 2019).

\subsubsection{Profiles}

Figure 16 shows global zonal profiles of cloud fraction for $\mathrm{Cu}, \mathrm{Sc}$, transitioning and all low-level clouds as observed by GOCCP, RL-GeoProf and 2BCCL, for the first time. As in Sect. 4.2.1, the transitioning clouds are not accounted for in the $\mathrm{Sc}$ and $\mathrm{Cu}$ cloud fractions of the CASCCAD datasets. Consistent with the map analysis, 2BCCL observations retrieve clouds in the low-levels more frequently than GOCCP (Fig. 16, top row), while the difference with RL-GeoProf is rather small compared to that with GOCCP (approximately 2 times larger). The large difference between GOCCP and RL-GeoProf cloud fractions in the low levels mostly comes from mid- and high-level topped clouds (e.g., frontal clouds in the extratropics and cumulonimbus and congestus clouds in the tropics, Fig. S9), which typically obscure CALIPSO vision by attenuating the lidar beam before it reaches the low levels. When separated into cloud types, GOCCP and RLGeoProf observations agree quite well for Sc and transitioning clouds globally (both in terms of pattern and amount) and for $\mathrm{Cu}$ clouds in the deep tropics $\left(15^{\circ} \mathrm{S} / \mathrm{N}\right)$ and down to $2 \mathrm{~km}$ in the subtropics and the extratropics (Fig. 16, second row). Between 2 and $1 \mathrm{~km}$, RL-GeoProf diagnoses more $\mathrm{Cu}$ than GOCCP. Such a difference is due to the different sensitivities of the lidar and radar instruments to clouds. The lidar signal becomes quickly attenuated by the optically and geometrically thick $\mathrm{Cu}$ - besides the attenuation from overlapping mid- or high clouds - whereas the CloudSat radar continues detecting clouds down to $1 \mathrm{~km}$. Below $1 \mathrm{~km}$ the surface clutter and the lidar attenuation make it difficult to retrieve a reliable cloud fraction.

Consistent with the case study and geographical analysis (Sect. 4.2.1), the 2BCCL product diagnoses far more (less) $\mathrm{Sc}(\mathrm{Cu})$ than the CASCCAD products, making the ratio of $\mathrm{Sc}$ to $\mathrm{Sc}$ and $\mathrm{Cu}$ clouds largely dominated by Sc (Fig. 16, bottom row). Furthermore, the vertical distribution of $\mathrm{Sc}$ and $\mathrm{Cu}$ clouds substantially differs from that of the CASCCAD products. The 2BCCL Sc clouds may extend up to $3 \mathrm{~km}$ while the majority of $\mathrm{Cu}$ clouds are concentrated around $1 \mathrm{~km}$ and almost exclusively in the tropics. This lack of $\mathrm{Cu}$ and excess of Sc clouds above $1 \mathrm{~km}$ in tropical subsidence regimes (Fig. 16, right column) is in disagreement with the CASCCAD products but also with previous studies focused on Sc regions (Cesana et al., 2019a, their Fig. 6) and Cu regions (Nuijens et al., 2015a, their Fig. 2; see also Fig. S1) (Nuijens et al., 2015a). 

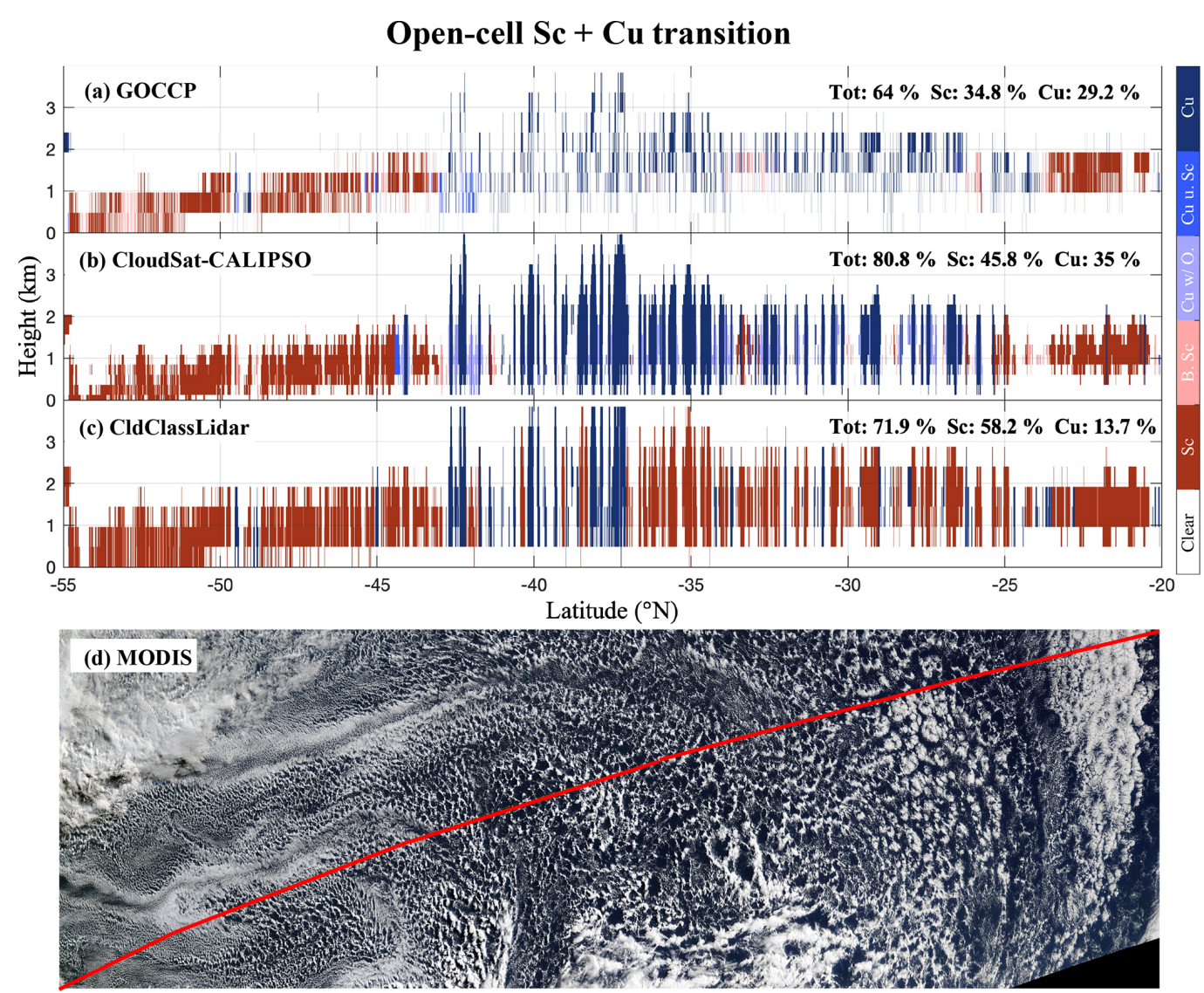

Figure 12. Same as Fig. 6 but for a typical open-cell Sc to $\mathrm{Cu}$ transitioning case overlapping the southeastern Pacific and the Southern Ocean ( 55 to $20^{\circ} \mathrm{S}, 14$ July 2008 21:10:19, daytime).

Therefore, one may think that $2 \mathrm{BCCL}$ overestimates (underestimates) $\mathrm{Sc}(\mathrm{Cu})$ clouds by misdiagnosing some $\mathrm{Cu}$ clouds as Sc clouds. On the contrary, the CASCCAD products better match typical profiles of $\mathrm{Sc}$ and $\mathrm{Cu}$ clouds.

Finally, these global-scale profiles are consistent with the physical processes controlling each type of cloud and measurements from previous literature. The Sc clouds - driven by radiative cooling - cap the PBL, a little higher than $1 \mathrm{~km}$ in the tropics and lower toward the poles, and their geometrical thickness is smaller than $1 \mathrm{~km}$. Averaged over the tropical subsidence regimes (and in the extratropics, Fig. S10), the Sc vertical cloud fraction peaks between $10 \%$ and $12 \%$, depending on the dataset, whereas it is larger for Sc deck areas only (not shown). On the contrary, $\mathrm{Cu}$ cloud base - forced by surface fluxes - mostly form below $1 \mathrm{~km}$, near the LCL, and vertically extend further aloft (around $2.5 \mathrm{~km}$ ). Although the $\mathrm{Cu}$ map cloud fraction is smaller than that of $\mathrm{Sc}$ in the tropics (Fig. 13, compare the second and third rows), their vertical cloud fraction is about the same, around $8 \%$, because they cover a larger domain (Fig. 16, right column). While the $\mathrm{Sc}$ vertical cloud fraction remains unchanged in the extratropics, its $\mathrm{Cu}$ and transitioning counterparts appear slightly larger, around $10 \%$ and between $6 \%$ and $10 \%$ (Fig. S10), respectively.

\section{Data availability}

The distinct GOCCP and RL-GeoProf CASCCAD statistical datasets (Cesana, 2019) can be downloaded on the GISS website (https://data.giss.nasa.gov/clouds/casccad/, last access: 5 November 2019) and on the zenodo website (https: //zenodo.org/record/2667637, last access: 5 November 2019; https://doi.org/10.5281/zenodo.2667637, Cesana, 2019).

GOCCP instantaneous profiles used to produce the CASCCAD dataset were downloaded from the CFMIP-OBS website (http://climserv.ipsl.polytechnique.fr/cfmip-obs/ Calipso_goccp.html, last access: 5 November 2019; Guzman et al., 2017). The CloudSat-CALIPSO data used to produce the CASCCAD dataset (i.e., 2B-GEOPROF and 2B-GEOPROF-LIDAR, Mace and Zhang, 2014) and the 2B-CLDCLASS-LIDAR (Wang et al., 2013) product were obtained from the CloudSat Data Processing Center (http: //www.cloudsat.cira.colostate.edu/data-products/level-2b, last access: 5 November 2019). 


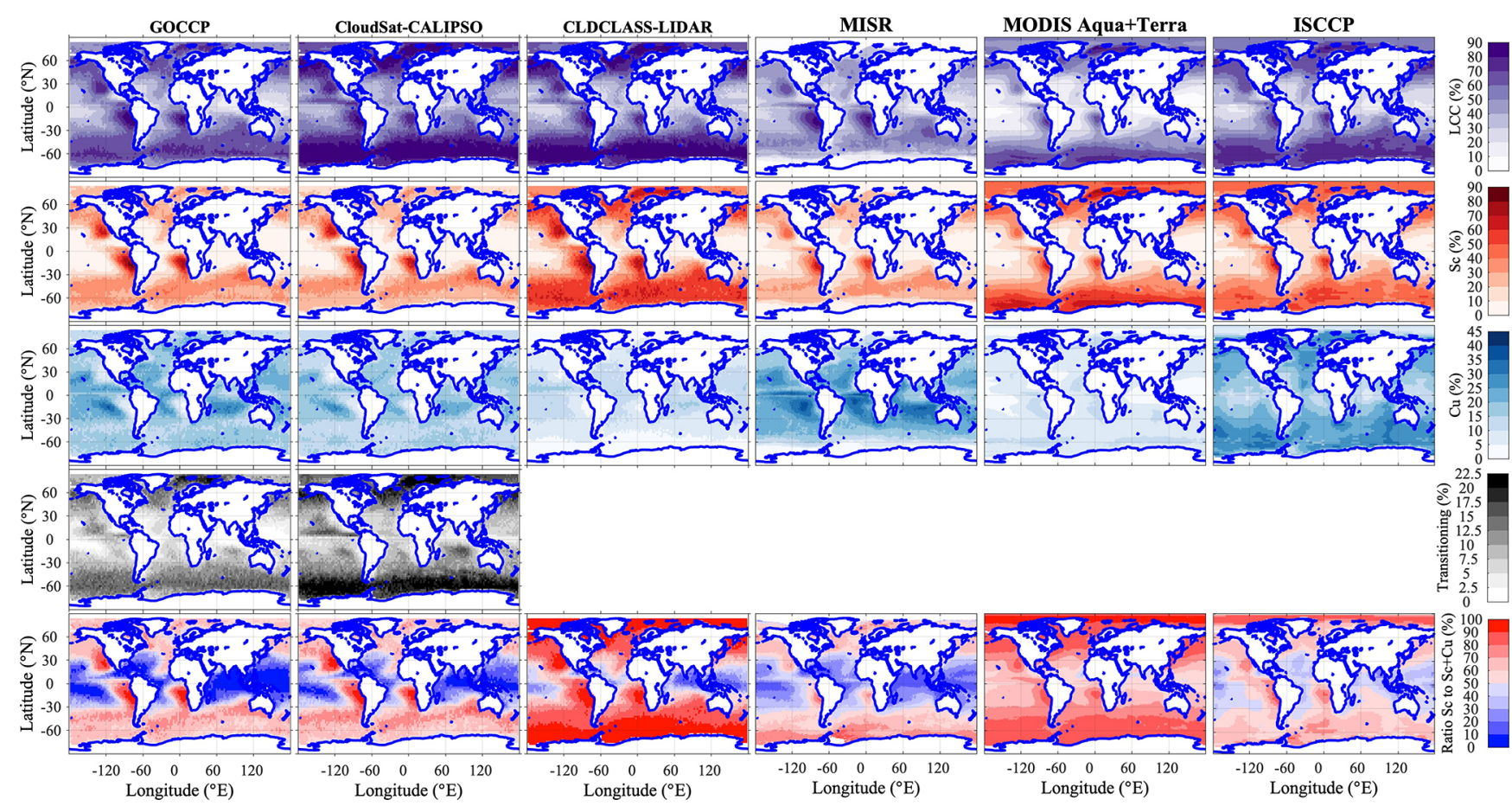

Figure 13. Maps ( $x$ axis, longitude, ${ }^{\circ} \mathrm{E} ; y$ axis, latitude, ${ }^{\circ} \mathrm{N}$ ) of (top to bottom) low, $\mathrm{Sc}, \mathrm{Cu}$, transitioning (i.e., broken $\mathrm{Sc}, \mathrm{Cu}$ under $\mathrm{Sc}$ and $\mathrm{Cu}$ with stratiform outflow), and the ratio Sc to Sc and Cu cloud fraction (\%) for (left to right) GOCCP (2007-2016), RL-GeoProf (2007-2010), 2BCCL (2007-2010), MISR (2003-2012), MODIS Terra and Aqua (2003-2015) and ISCCP (1983-2008). Different color bars are used to better separate each type of cloud. Note that for active-sensor satellites, the low category accounts for all clouds present below $3.36 \mathrm{~km}$ regardless of their cloud top height, hence the sum of $\mathrm{Sc}, \mathrm{Cu}$ and transitioning cloud fraction can be smaller than the low cloud fraction. All datasets are averaged onto a $2.5^{\circ} \times 2.5^{\circ}$ grid.

The ISCCP WS data were obtained from the official ISCCP website (https://isccp.giss.nasa.gov/wstates/gcluster. html, last access: 5 November 2019; Tselioudis et al., 2013) and the matching total cloud fraction from the CFMIP-OBS website (https://climserv.ipsl.polytechnique.fr/ cfmip-obs/Isccp.html, last access: 5 November 2019; Pincus et al., 2012). The MODIS CR and matching total cloud fraction were provided by Lazaros Oreopoulos and Nayeong Cho, who can make them available upon request by contacting them at Lazaros.Oreopoulos@ nasa.gov.

\section{Conclusions}

In this paper, we document spatial distributions and profiles of stratocumulus $(\mathrm{Sc})$, cumulus $(\mathrm{Cu})$ and transitioning (i.e., broken $\mathrm{Sc}, \mathrm{Cu}$ under $\mathrm{Sc}$ and $\mathrm{Cu}$ with stratiform outflow) clouds on a global scale. To this end, we design a discrimination algorithm (DA; Sect. 3) that distinguishes Sc and $\mathrm{Cu}$ based on four observable cloud properties: cloud top height $(\mathrm{CTH})$, horizontal cloud fraction $(\mathrm{HCF})$, vertical cloud fraction variability (VCF) and horizontal continuity. These simple criteria are sufficient to characterize the distinctive shape of $\mathrm{Cu}$, which have a limited horizontal extent and highly variable $\mathrm{CTH}$ as opposed to Sc, which cover larger areas and have a small and stable geometrical thickness. The DA is utilized separately on instantaneous profiles of active-sensor CALIPSO-GOCCP (Guzman et al., 2017) and CloudSat-CALIPSO combined observations (RL-GeoProf; Cesana et al., 2019b; Mace and Zhang, 2014) to create the distinct GOCCP and RL-GeoProf Cumulus And Stratocumulus CloudSat-CALIPSO Datasets (CASCCAD).

The choice of DA parameters is then investigated in $\mathrm{Cu}$, $\mathrm{Sc}$ and $\mathrm{Sc}-\mathrm{Cu}$ transition case studies (Sect. 4.1), supported by additional viewing from MODIS true reflectance and full resolution CALIPSO VFM $(\Delta z=30 \mathrm{~m})$. The results show that the DA robustly captures $\mathrm{Sc}, \mathrm{Cu}$ and $\mathrm{Sc}-\mathrm{Cu}$ transition clouds although the choice of VCF and HCF thresholds may slightly affect the $\mathrm{Sc}-\mathrm{Cu}$ partitioning in open-Sc and $\mathrm{Cu}$ regions.

The distinct GOCCP and RL-GeoProf CASCCAD globalscale statistics (Sect. 4.2) are then compared to a subset of passive-sensor satellite datasets and to the only existing CloudSat-CALIPSO cloud-type climatology 2BCLDCLASS-LIDAR (2BCCL, Sassen and Wang, 2008). In passive-sensor satellite observations, $\mathrm{Sc}$ and $\mathrm{Cu}$ coexist everywhere and no region is fully dominated by a particular type of cloud (Fig. 12, bottom row) when distinguished only based on their cloud optical thickness, while Sc are mostly 

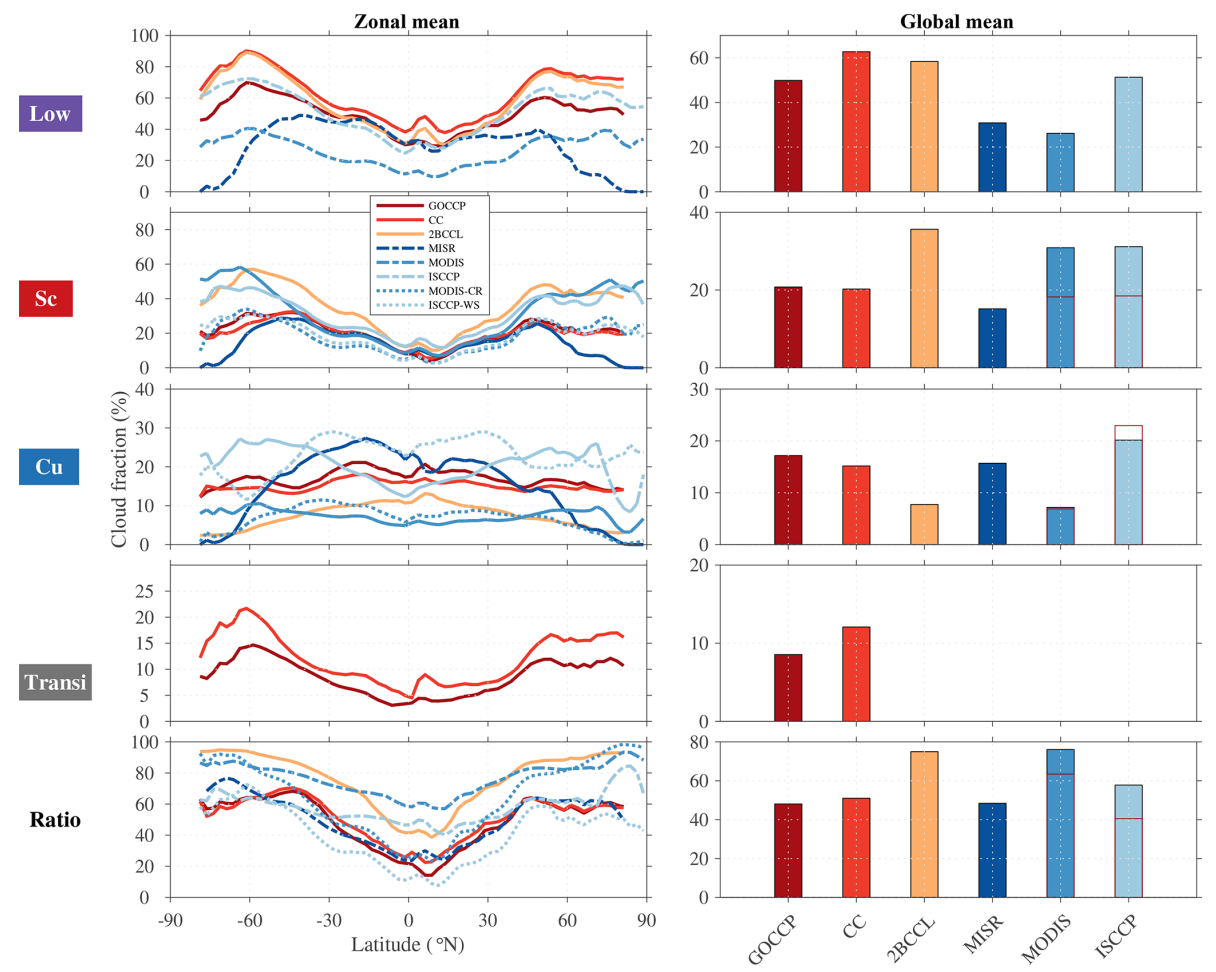

Figure 14. Global zonal mean (\%, left) and global area-weighted mean (\%, right) of low, $\mathrm{Sc}, \mathrm{Cu}$, transitioning (i.e., broken $\mathrm{Sc}$, Cu under Sc and $\mathrm{Cu}$ with stratiform outflow), and the ratio $\mathrm{Sc}$ to $\mathrm{Sc}-\mathrm{Cu}$ clouds - from the top to the bottom - for all the satellite datasets using the same time period as in Fig. 13. Active-sensor observations are represented in solid lines as opposed to dashed lines for COT-CTP passive-sensor observations and dotted lines for clustering passive-sensor observations. The clustering area-weighted means are represented by transparent bars with red borders. Note that the $y$ axes are different in every subplot. All datasets are averaged onto a $2.5^{\circ} \times 2.5^{\circ}$ grid.

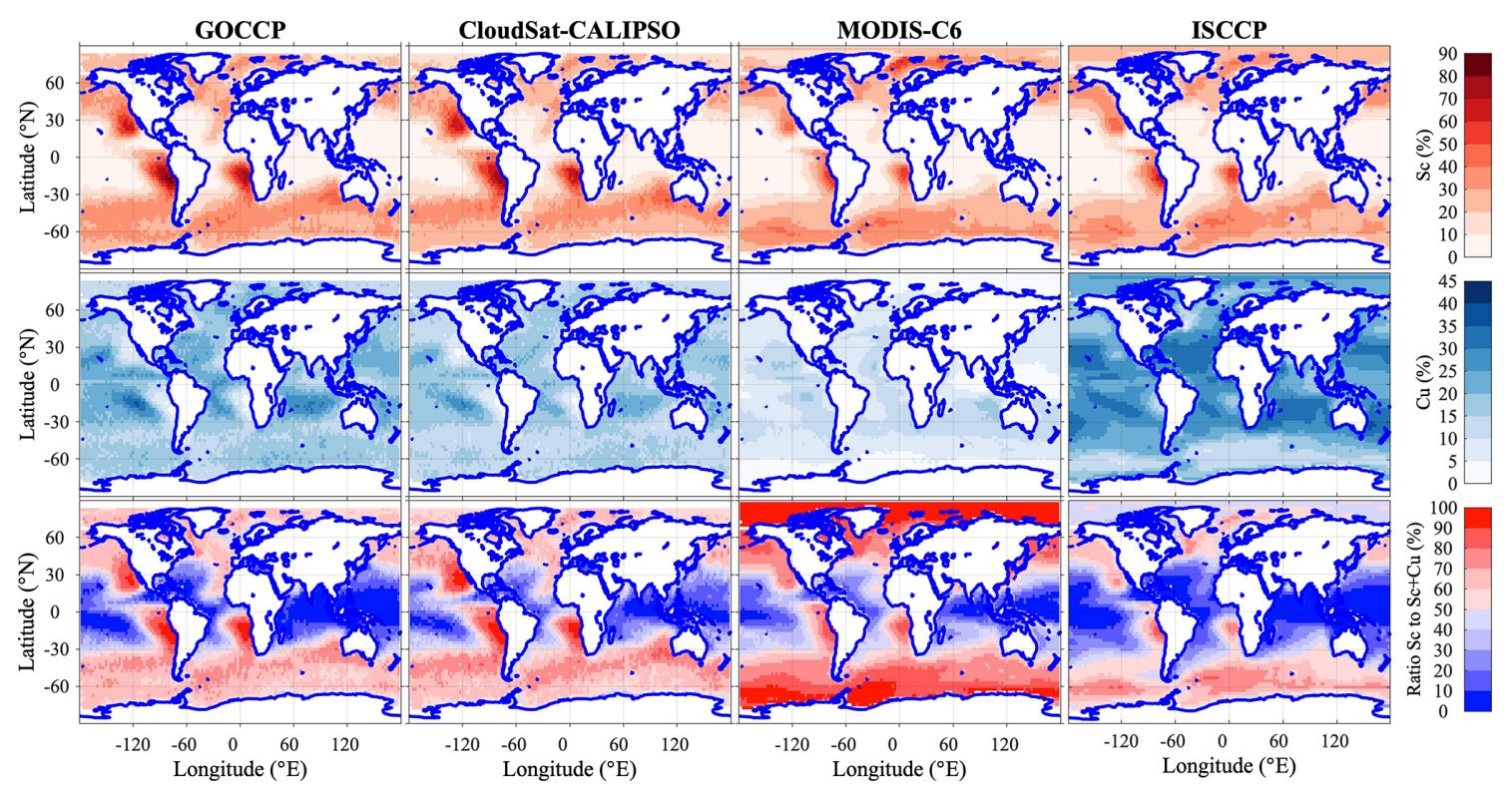

Figure 15. Similar to Fig. 13, maps ( $x$ axis, longitude, ${ }^{\circ} \mathrm{E} ; y$ axis, latitude, ${ }^{\circ} \mathrm{N}$ ) of (top to bottom) $\mathrm{Sc}, \mathrm{Cu}$ and the ratio $\mathrm{Sc}$ to $\mathrm{Sc}$ and $\mathrm{Cu}$ cloud fraction (\%) for (left to right) GOCCP (2007-2016), RL-GeoProf (2007-2010), MODIS Terra and Aqua cloud regime (2003-2015), and ISCCP weather state (2001-2008). 

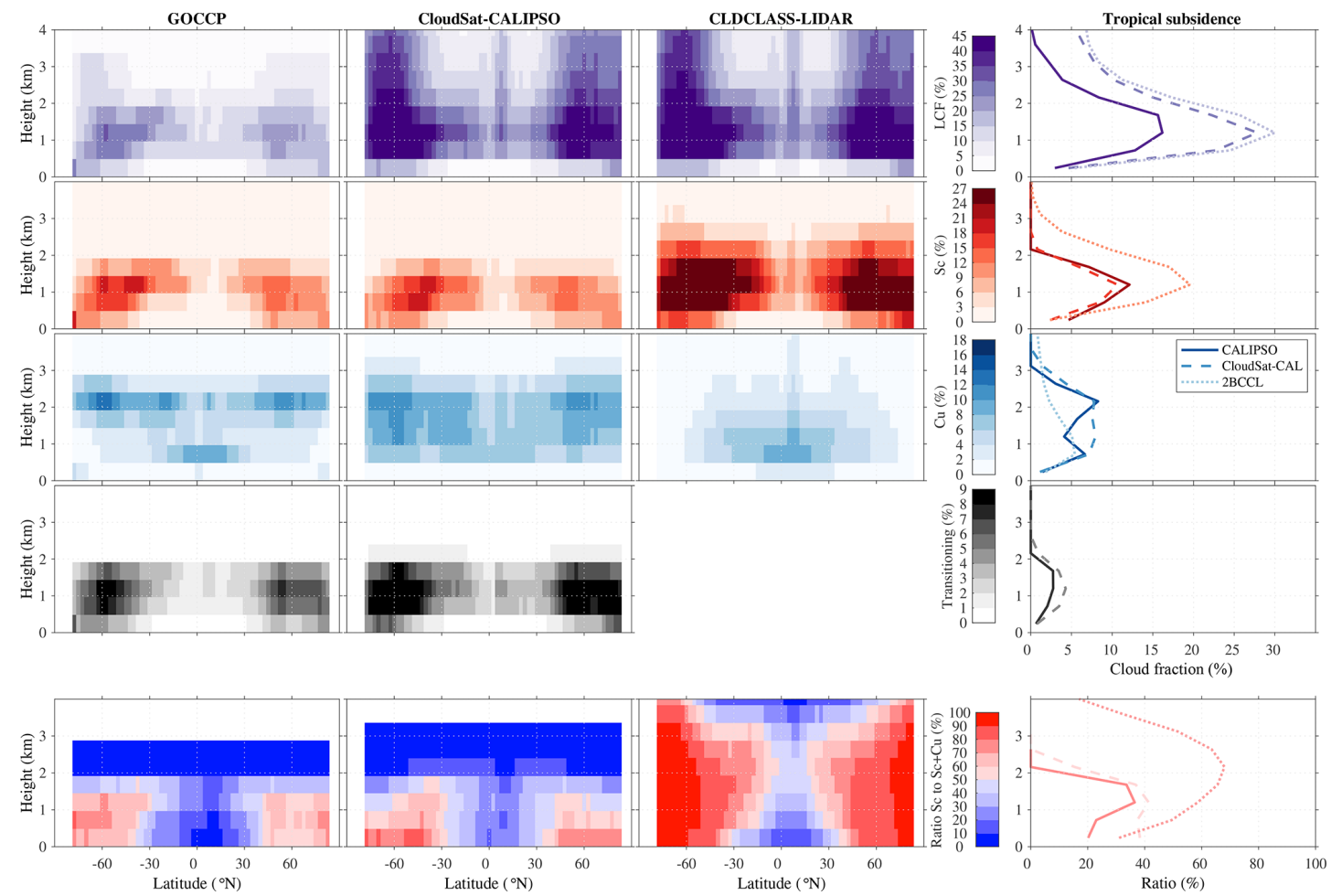

Figure 16. Zonal profiles ( $x$ axis, latitude, ${ }^{\circ} \mathrm{N} ; y$ axis, height, $\mathrm{km}$ ) of low (first row), Sc (second row), $\mathrm{Cu}$ (third row) and transitioning (i.e., broken $\mathrm{Sc}, \mathrm{Cu}$ under $\mathrm{Sc}$ and $\mathrm{Cu}$ with stratiform outflow; fourth row) cloud fraction (\%) for GOCCP (first column), RL-GeoProf (second column) and 2BCCL (third column). As in Fig. 13, different color bars are used to better separate each type of cloud. The corresponding profiles for tropical subsidence regimes $\left(\omega 500>10 \mathrm{hPad}^{-1}\right.$ between $35^{\circ} \mathrm{S}$ and $\mathrm{N}$ following Cesana et al., 2019a) are represented in the fourth column for GOCCP (solid line), RL-GeoProf (dashed line) and 2BCCL (dotted line). Note that extratropical profiles are shown in Fig. S10.

confined to specific regions (off the west coast of continents) with the more recent clustering approach. On the contrary, Sc clouds largely dominate the global statistics from the 2BCCL point of view, which may misdiagnose a substantial portion of $\mathrm{Cu}$ clouds as Sc clouds in the trade-wind and extratropical regions. Interestingly, the CASCCAD observations depict tropical oceans being almost exclusively dominated by $\mathrm{Cu}$ clouds (around $20 \%$ on average and up to $40 \%$ ), while the oceans off the west coasts of the continents are mostly covered by Sc clouds (50\% to $85 \%$ ), with transitioning clouds in between $(10 \%$ to $15 \%)$. Our results provide a broader context to earlier findings from ground-based and field campaigns (Albrecht et al., 2019, 1995; Bretherton et al., 2010; Comstock et al., 2004; Garay et al., 2008; Wood, 2012; Zhou et al., 2015; Zuidema et al., 2009). For example, our globally averaged profiles of $\mathrm{Cu}$ cloud fraction over the tropical oceans are almost identical to that found by Nuijens et al. (2015a) over Barbados, in terms of shape (cloud base below $1 \mathrm{~km}$ and cloud top above $2 \mathrm{~km}$ ) and frequency of occurrence $(\sim 10 \%)$. Another interesting result concerns the distribution and magnitude of Sc cloud fraction. Our results indicate that the Sc clouds occur up to $85 \%$ of the time over Sc deck areas compared to $60 \%$ in earlier studies (i.e., Wood,
2012) and that their presence in trade-wind regions is negligible as opposed to a $20 \%$ cloud frequency (i.e., Wood, 2012). Furthermore, our analysis indicates that the optical thickness, albeit useful, is not a sufficient parameter to discriminate $\mathrm{Cu}$ from Sc clouds, in agreement with previous literature (e.g., Pincus et al., 1999).

Finally, one of the reasons we developed CASCCAD is to provide an improved observational constraint for low-level cloud feedbacks in GCMs. Although the CASCCAD DA cannot be implemented in a lidar or radar simulator (Chepfer et al., 2008; Marchand et al., 2008), it is still possible to use CASCCAD datasets for model evaluation because (i) both the convective and stratiform cloud fraction are provided as inputs to the lidar simulator and could be easily saved separately rather than summed up and (ii) a simulator is not necessarily needed for model-to-observation comparison of $\mathrm{Cu}$ and $\mathrm{Sc}$ clouds over the tropical oceans, because we identify the different cloud modes explicitly and we can select regimes in which lidar attenuation is negligible (e.g., $\omega_{500}>0 \mathrm{hPad}^{-1}$, Cesana et al., 2019a). Therefore, the two CASCCAD datasets make it possible to evaluate the shallow convection (Cu type) and boundary layer ( $\mathrm{Sc}$ type) clouds in state-of-the art climate models, which are typ- 
ically generated by distinct parameterizations (i.e., Cesana et al., 2019a), but also in unified-scheme turbulence models, in which $\mathrm{Sc}$ and $\mathrm{Cu}$ are still generated by distinct physical mechanisms (eddy diffusion for $\mathrm{Sc}$ and mass flux for $\mathrm{Cu}$, e.g., Köhler et al., 2011). In such parameterizations, the existence of shallow convection is determined by a large-scale environmental index of inversion strength. In other unified turbulence schemes, the diagnosis of model success is achieved by defining $\mathrm{Sc}, \mathrm{Sc}-\mathrm{Cu}$, and $\mathrm{Cu}$ regimes in terms of inversion strength (Bogenschutz and Krueger, 2013). We suggest that a dataset such as CASCCAD that directly identifies these physically different cloud types is a better metric to use to judge model realism and fidelity. By doing so, one could also assess the radiative contribution of $\mathrm{Sc}$ and $\mathrm{Cu}$ clouds to climate and potentially improve our understanding of low-level cloud feedbacks.

Supplement. The supplement related to this article is available online at: https://doi.org/10.5194/essd-11-1745-2019-supplement.

Author contributions. GC designed the study, developed the products and carried out the analysis with inputs from ADDG and HC. GC wrote the manuscript with contributions from ADDG and $\mathrm{HC}$.

Competing interests. The authors declare that they have no conflict of interest.

Acknowledgements. Grégory Cesana and Anthony D. Del Genio were supported by a CloudSat-CALIPSO RTOP at the NASA Goddard Institute for Space Studies. The authors would like to thank NASA and CNES for giving access to CALIPSO and CloudSat observations, as well as Climserv for giving access to CALIPSOGOCCP observations and for providing computing resources. The authors also thank Lazaros Oreopoulos and George Tselioudis for their help in processing the MODIS CR and ISCCP WS datasets, respectively. Grégory Cesana thanks Zhien Wang for his help in understanding the 2B-CLDCLASS-LIDAR dataset and Andy Ackerman, Ann Fridlind, Max Kelley and Greg Elsaesser for helpful comments and discussion. Finally, the authors thank the two anonymous reviewers and the editor for the helpful comments.

Financial support. This research has been supported by the National Aeronautics and Space Administration (RTOP grant).

Review statement. This paper was edited by Alexander Kokhanovsky and reviewed by two anonymous referees.

\section{References}

Albrecht, B., Ghate, V., Mohrmann, J., Wood, R., Zuidema, P., Bretherton, C., Schwartz, C., Eloranta, E., Glienke, S., Donaher, S., Sarkar, M., McGibbon, J., Nugent, A. D., Shaw, R. A., Fugal, J., Minnis, P., Paliknoda, R., Lussier, L., Jensen, J., Vivekanandan, J., Ellis, S., Tsai, P., Rilling, R., Haggerty, J., Campos, T., Stell, M., Reeves, M., Beaton, S., Allison, J., Stossmeister, G., Hall, S., and Schmidt, S.: Cloud system evolution in the trades (CSET)following the evolution of boundary layer cloud systems with the NSF-NCAR GV, B. Am. Meteorol. Soc., 100, 93-121, https://doi.org/10.1175/BAMS-D-17-0180.1, 2019.

Albrecht, B. A., Bretherton, C. S., Johnson, D., Scubert, W. H., and Frisch, A. S.: The Atlantic Stratocumulus Transition Experiment - ASTEX, B. Am. Meteorol. Soc., 76, 889-904, https://doi.org/10.1175/15200477(1995)076<0889:TASTE>2.0.CO;2, 1995.

Bogenschutz, P. A. and Krueger, S. K.: A simplified PDF parameterization of subgrid-scale clouds and turbulence for cloudresolving models, J. Adv. Model. Earth Syst., 5, 195-211, https://doi.org/10.1002/jame.20018, 2013.

Bretherton, C. S.: Insights into low-latitude cloud feedbacks from high-resolution models, Philos. Trans. R. Soc. A Math. Phys. Eng. Sci., 373, 2054, https://doi.org/10.1098/rsta.2014.0415, 2015.

Bretherton, C. S., Wood, R., George, R. C., Leon, D., Allen, G., and Zheng, X.: Southeast Pacific stratocumulus clouds, precipitation and boundary layer structure sampled along $20^{\circ} \mathrm{S}$ during VOCALS-REx, Atmos. Chem. Phys., 10, 10639-10654, https://doi.org/10.5194/acp-10-10639-2010, 2010.

Cesana, G.: CASCCAD: Cumulus And Stratocumulus Cloudsat-CAlipso Dataset, Data set, Zenodo, https://doi.org/10.5281/zenodo.2667637, 2019.

Cesana, G. and Waliser, D. E.: Characterizing and understanding systematic biases in the vertical structure of clouds in CMIP5/CFMIP2 models, Geophys. Res. Lett., 43, 10538-10546, https://doi.org/10.1002/2016GL070515, 2016.

Cesana, G., Chepfer, H., Winker, D., Getzewich, B., Cai, X., Jourdan, O., Mioche, G., Okamoto, H., Hagihara, Y., Noel, V., and Reverdy, M.: Using in situ airborne measurements to evaluate three cloud phase products derived from CALIPSO, J. Geophys. Res., 121, 5788-5808, https://doi.org/10.1002/2015JD024334, 2016.

Cesana, G., Del Genio, A. D., Ackerman, A. S., Kelley, M., Elsaesser, G., Fridlind, A. M., Cheng, Y., and Yao, M.-S.: Evaluating models' response of tropical low clouds to SST forcings using CALIPSO observations, Atmos. Chem. Phys., 19, 2813 2832, https://doi.org/10.5194/acp-19-2813-2019, 2019a.

Cesana, G., Waliser, D. E., Henderson, D., L'Ecuyer, T. S., Jiang, X., and Li, J.-L. F.: The Vertical Structure of Radiative Heating Rates: A Multimodel Evaluation Using ATrain Satellite Observations, J. Climate, 32, 1573-1590, https://doi.org/10.1175/JCLI-D-17-0136.1, 2019b.

Chepfer, H., Bony, S., Winker, D., Chiriaco, M., Dufresne, J.-L., and Sèze, G.: Use of CALIPSO lidar observations to evaluate the cloudiness simulated by a climate model, Geophys. Res. Lett., 35, L15704, https://doi.org/10.1029/2008GL034207, 2008.

Chepfer, H., Bony, S., Winker, D., Cesana, G., Dufresne, J. L., Minnis, P., Stubenrauch, C. J., and Zeng, S.: The GCM-Oriented 
CALIPSO Cloud Product (CALIPSO-GOCCP), J. Geophys. Res., 115, D00H16, https://doi.org/10.1029/2009JD012251, 2010.

Chepfer, H., Cesana, G., Winker, D., Getzewich, B., Vaughan, M., and Liu, Z.: Comparison of Two Different Cloud Climatologies Derived from CALIOP-Attenuated Backscattered Measurements (Level 1): The CALIPSO -ST and the CALIPSO -GOCCP, J. Atmos. Ocean. Technol., 30, 725-744, https://doi.org/10.1175/JTECH-D-12-00057.1, 2013.

Comstock, K. K., Wood, R., Yuter, S. E., and Bretherton, C. S.: Reflectivity and rain rate in and below drizzling stratocumulus, Q. J. Roy. Meteorol. Soc., 130, 2891-2918, https://doi.org/10.1256/qj.03.187, 2004.

Garay, M. J., De Szoeke, S. P., and Moroney, C. M.: Comparison of marine stratocumulus cloud top heights in the southeastern Pacific retrieved from satellites with coincident ship-based observations, J. Geophys. Res.-Atmos., 113, 1-13, https://doi.org/10.1029/2008JD009975, 2008.

Guzman, R., Chepfer, H., Noel, V., de Guélis, T. V., Kay, J. E., Raberanto, P., Cesana, G., Vaughan, M. A., and Winker, D. M.: Direct atmosphere opacity observations from CALIPSO provide new constraints on cloud-radiation interactions, J. Geophys. Res., 122, 1066-1085, https://doi.org/10.1002/2016JD025946, 2017

Hahn, C. J., Rossow, W. B., and Warren, S. G.: ISCCP Cloud Properties Associated with Standard Cloud Types Identified in Individual Surface Observations, J. Climate, 14, 11-28, https://doi.org/10.1175/15200442(2001)014<0011:ICPAWS>2.0.CO;2, 2001.

Huang, L., Jiang, J. H., Wang, Z., Su, H., Deng, M., and Massie, S.: Climatology of cloud water content associated with different cloud types observed by A-Train satellites, J. Geophys. Res.-Atmos., 120, 4196-4212, https://doi.org/10.1002/2014JD022779, 2015.

Kikuchi, M., Okamoto, H., Sato, K., Suzuki, K., Cesana, G., Hagihara, Y., Takahashi, N., Hayasaka, T., and Oki, R.: Development of Algorithm for Discriminating Hydrometeor Particle Types With a Synergistic Use of CloudSat and CALIPSO, J. Geophys. Res.-Atmos., 122, 11022-11044, https://doi.org/10.1002/2017JD027113, 2017.

King, M. D., Platnick, S., Menzel, W. P., Ackerman, S. A., and Hubanks, P. A.: Spatial and Temporal Distribution of Clouds Observed by MODIS Onboard the Terra and Aqua Satellites, IEEE Trans. Geosci. Remote Sens., 51, 3826-3852, https://doi.org/10.1109/TGRS.2012.2227333, 2013.

Klein, S. A. and Hall, A.: Emergent Constraints for Cloud Feedbacks, Curr. Clim. Chang. Reports, 1, 276-287, https://doi.org/10.1007/s40641-015-0027-1, 2015.

Klein, S. A. and Hartmann, D. L.: Klein_Hartmann_1993.pdf, J. Climate, 6, 1587-1606, 1993.

Klein, S. A., Hall, A., Norris, J. R., and Pincus, R.: Low-Cloud Feedbacks from Cloud-Controlling Factors: A Review, Surv. Geophys., 38, 1307-1329, https://doi.org/10.1007/s10712-0179433-3, 2017.

Köhler, M., Ahlgrimm, M., and Beljaars, A.: Unified treatment of dry convective and stratocumulus-topped boundary layers in the ECMWF model, Q. J. Roy. Meteorol. Soc., 137, 43-57, https://doi.org/10.1002/qj.713, 2011.
Lacour, A., Chepfer, H., Shupe, M. D., Miller, N. B., Noel, V., Kay, J., Turner, D. D., and Guzman, R.: Greenland Clouds Observed in CALIPSO -GOCCP: Comparison with Ground-Based Summit Observations, J. Climate, 30, 6065-6083, https://doi.org/10.1175/JCLI-D-16-0552.1, 2017.

Lamer, K., Kollias, P., and Nuijens, L.: Observations of the variability of shallow trade wind cumulus cloudiness and mass flux, J. Geophys. Res.-Atmos., 120, 6161-6178, https://doi.org/10.1002/2014JD022950, 2015.

Liu, D., Liu, Q., Qi, L., and Fu, Y.: Oceanic single-layer warm clouds missed by the cloud profiling radar as inferred from MODIS and CALIOP measurements, J. Geophys. Res., 121, 12947-12965, https://doi.org/10.1002/2016JD025485, 2016.

Mace, G. G. and Wrenn, F. J.: Evaluation of the hydrometeor layers in the East and West Pacific within ISCCP cloud-top pressureoptical depth bins using merged CloudSat and CALIPSO data, J. Climate, 26, 9429-9444, https://doi.org/10.1175/JCLI-D-1200207.1, 2013.

Mace, G. G. and Zhang, Q.: The CloudSat radar-lidar geometrical profile product (RL-GeoProf): Updates, improvements, and selected results, J. Geophys. Res.-Atmos., 119, 9441-9462, https://doi.org/10.1002/2013JD021374, 2014.

Marchand, R., Mace, G. G., Ackerman, T., and Stephens, G.: Hydrometeor detection using Cloudsat - An earth-orbiting 94GHz cloud radar, J. Atmos. Ocean. Technol., 25, 519-533, https://doi.org/10.1175/2007JTECHA1006.1, 2008.

Marchand, R., Haynes, J., Mace, G. G., Ackerman, T., and Stephens, G.: A comparison of simulated cloud radar output from the multiscale modeling framework global climate model with CloudSat cloud radar observations, J. Geophys. Res., 114, D00A20, https://doi.org/10.1029/2008JD009790, 2009.

Marchand, R., Ackerman, T., Smyth, M., and Rossow, W. B.: A review of cloud top height and optical depth histograms from MISR, ISCCP, and MODIS, J. Geophys. Res.-Atmos., 115, 125, https://doi.org/10.1029/2009JD013422, 2010.

McCoy, D. T., Eastman, R., Hartmann, D. L., and Wood, R.: The change in low cloud cover in a warmed climate inferred from AIRS, MODIS, and ERA-interim, J. Climate, 30, 3609-3620, https://doi.org/10.1175/JCLI-D-15-0734.1, 2017.

Mcgill, M. J., Vaughan, M. A., Trepte, C. R., Hart, W. D., Hlavka, D. L., Winker, D. M., and Kuehn, R.: Airborne validation of spatial properties measured by the CALIPSO lidar, J. Geophys. Res.-Atmos., 112, 1-8, https://doi.org/10.1029/2007JD008768, 2007.

Nuijens, L., Medeiros, B., Sandu, I., and Ahlgrimm, M.: Observed and modeled patterns of covariability between low-level cloudiness and the structure of the tradewind layer, J. Adv. Model. Earth Syst., 7, 1741-1764, https://doi.org/10.1002/2015MS000483, 2015a.

Nuijens, L., Medeiros, B., Sandu, I., and Ahlgrimm, M.: The behavior of trade-wind cloudiness in observations and models: The major cloud components and their variability, J. Adv. Model. Earth Syst., 7, 600-616, https://doi.org/10.1002/2014MS000390, $2015 b$.

Oreopoulos, L., Cho, N., Lee, D., Kato, S., and Huffman, G. J.: An examination of the nature of global MODIS cloud regimes, J. Geophys. Res.-Atmos., 119, 8362-8383, https://doi.org/10.1002/2013JD021409, 2014. 
Oreopoulos, L., Cho, N., and Lee, D.: A global survey of apparent aerosol-cloud interaction signals, J. Geophys. Res., submitted, 2019.

Pincus, R., McFarlane, S. A., and Klein, S. A.: Albedo bias and the horizontal variability of clouds in subtropical marine boundary layers: Observations from ships and satellites, J. Geophys. Res.-Atmos., 104, 6183-6191, https://doi.org/10.1029/1998JD200125, 1999.

Pincus, R., Platnick, S., Ackerman, S. A., Hemler, R. S. and Hofmann, R. J. P.: Reconciling Simulated and Observed Views of Clouds: \{MODIS\}, \{ISCCP\}, and the Limits of Instrument Simulators, J. Climate, 25, 4699-4720, https://doi.org/10.1175/jcli-d11-00267.1, 2012.

Rauber, R. M., Stevens, B., Ochs, H. T., Knight, C., Albrecht, B. A., Blyth, A. M., Fairall, C. W., and Jensen, J. B.: Over the ocean: The RICO campaign, B. Am. Meteorol. Soc., 88, 1912-1928, https://doi.org/10.1175/BAMS-88-12-1912, 2007.

Rémillard, J., Kollias, P., Luke, E., and Wood, R.: Marine boundary layer cloud observations in the Azores, J. Climate, 25, 73817398, https://doi.org/10.1175/JCLI-D-11-00610.1, 2012.

Rodts, S. M. A., Duynkerke, P. G., and Jonker, H. J. J.: Size Distributions and Dynamical Properties of Shallow Cumulus Clouds from Aircraft Observations and Satellite Data, J. Atmos. Sci., 60, 1895-1912, https://doi.org/10.1175/15200469(2003)060<1895:SDADPO>2.0.CO;2, 2003.

Rossow, W. B. and Schiffer, R. A.: ISCCP Cloud Data Products, B. Am. Meteorol. Soc., 72, 2-20, https://doi.org/10.1175/15200477(1991)072<0002:ICDP>2.0.CO;2, 1991.

Rossow, W. B. and Schiffer, R. A.: Advances in Understanding Clouds from ISCCP, B. Am. Meteorol. Soc., $\quad 80, \quad 2261-2287$, https://doi.org/10.1175/15200477(1999)080<2261:AIUCFI>2.0.CO;2, 1999.

Sassen, K. and Wang, Z.: Classifying clouds around the globe with the CloudSat radar?: 1-year of results, Geophys. Res. Lett., 35, 1-5, https://doi.org/10.1029/2007GL032591, 2008.

Stephens, G. L., Vane, D. G., Boain, R. J., Mace, G. G., Sassen, K., Wang, Z., Illingworth, A. J., O'connor, E. J., Rossow, W. B., Durden, S. L., Miller, S. D., Austin, R. T., Benedetti, A., and Mitrescu, C.: THE CLOUDSAT MISSION AND THE A-TRAIN, B. Am. Meteorol. Soc., 83, 1771-1790, https://doi.org/10.1175/BAMS-83-12-1771, 2002.

Teixeira, J., Cardoso, S., Bonazzola, M., Cole, J., DelGenio, A., DeMott, C., Franklin, C., Hannay, C., Jakob, C., Jiao, Y., Karlsson, J., Kitagawa, H., Köhler, M., Kuwano-Yoshida, A., LeDrian, C., Li, J., Lock, A., Miller, M. J., Marquet, P., Martins, J., Mechoso, C. R., Meijgaard, E. v., Meinke, I., Miranda, P. M. A., Mironov, D., Neggers, R., Pan, H. L., Randall, D. A., Rasch, P. J., Rockel, B., Rossow, W. B., Ritter, B., Siebesma, A. P., Soares, P. M. M., Turk, F. J., Vaillancourt, P. A., Von Engeln, A., and Zhao, M.: Tropical and Subtropical Cloud Transitions in Weather and Climate Prediction Models: The GCSS/WGNE Pacific Cross-Section Intercomparison (GPCI), J. Climate, 24, 5223-5256, https://doi.org/10.1175/2011JCLI3672.1, 2011.
Thorsen, T. J., Fu, Q., and Comstock, J. M.: Cloud effects on radiative heating rate profiles over Darwin using ARM and A-train radar/lidar observations, J. Geophys. Res.-Atmos., 118, 56375654, https://doi.org/10.1002/jgrd.50476, 2013.

Tselioudis, G., Rossow, W., Zhang, Y., and Konsta, D.: Global weather states and their properties from passive and active satellite cloud retrievals, J. Climate, 26, 7734-7746, https://doi.org/10.1175/JCLI-D-13-00024.1, 2013.

Vaughan, M. A., Powell, K. A., Winker, D. M., Hostetler, C. A., Kuehn, R. E., Hunt, W. H., Getzewich, B. J., Young, S. A., Liu, Z., and McGill, M. J.: Fully Automated Detection of Cloud and Aerosol Layers in the CALIPSO Lidar Measurements, J. Atmos. Ocean. Technol., 26, 2034-2050, https://doi.org/10.1175/2009JTECHA1228.1, 2009.

Wang, Z., Vane, D., Stephens, G., and Reinke, D.: Level 2 Combined Radar and Lidar Cloud Scenario Classification Product Process Description and Interface Control document, CloudSat Proj. Jet Propuls. Lab. Pasadena, (D), 2013.

Warren, S. G., Hahn, C. H., London, J., Chervin, R. M., and Jenne, R. L.: Global distribution of total cloud cover and cloud type amounts over the ocean, NCAR Tech. Note TN-317STR, 212 pp., https://doi.org/10.5065/D6QC01D1, 1988.

Winker, D. M., Pelon, J., Coakley, J. A., Ackerman, S. A., Charlson, R. J., Colarco, P. R., Flamant, P., Fu, Q., Hoff, R. M., Kittaka, C., Kubar, T. L., Le Treut, H., Mccormick, M. P., Mégie, G., Poole, L., Powell, K., Trepte, C., Vaughan, M. A., and Wielicki, B. A.: The CALIPSO Mission, B. Am. Meteorol. Soc., 91, 1211-1230, https://doi.org/10.1175/2010BAMS3009.1, 2010.

Wood, R.: Stratocumulus Clouds, Mon. Weather Rev., 140, 23732423, https://doi.org/10.1175/MWR-D-11-00121.1, 2012.

Wyant, M. C., Bretherton, C. S., Rand, H. A., and Stevens, D. E.: Numerical Simulations and a Conceptual Model of the Stratocumulus to Trade Cumulus Transition, J. Atmos. Sci., 54, 168-192, https://doi.org/10.1175/15200469(1997)054<0168:NSAACM>2.0.CO;2, 1997.

Zelinka, M. D., Zhou, C., and Klein, S. A.: Insights from a refined decomposition of cloud feedbacks, Geophys. Res. Lett., 43, 9259-9269, https://doi.org/10.1002/2016GL069917, 2016.

Zhang, Y. and Klein, S. A.: Factors Controlling the Vertical Extent of Fair-Weather Shallow Cumulus Clouds over Land: Investigation of Diurnal-Cycle Observations Collected at the ARM Southern Great Plains Site, J. Atmos. Sci., 70, 1297-1315, https://doi.org/10.1175/JAS-D-12-0131.1, 2013.

Zhou, X., Kollias, P., and Lewis, E. R.: Clouds, precipitation, and marine boundary layer structure during the MAGIC field campaign, J. Climate, 28, 2420-2442, https://doi.org/10.1175/JCLID-14-00320.1, 2015.

Zuidema, P., Painemal, D., De Szoeke, S., and Fairall, C.: Stratocumulus cloud-top height estimates and their climatic implications, J. Climate, 22, 4652-4666, https://doi.org/10.1175/2009JCLI2708.1, 2009. 